\title{
Deletion of Atg22 gene contributes to reduce programmed cell death induced by acetic acid stress in Saccharomyces cerevisiae
}

\author{
Jingjin $\mathrm{Hu}^{1+}$, Yachen Dong ${ }^{1+}$, Wei Wang ${ }^{3}$, Wei Zhang ${ }^{2^{*}}$, Hanghang Lou ${ }^{1}$ and Qihe Chen ${ }^{1^{*}}$ (D)
}

\begin{abstract}
Background: Programmed cell death (PCD) induced by acetic acid, the main by-product released during cellulosic hydrolysis, cast a cloud over lignocellulosic biofuel fermented by Saccharomyces cerevisiae and became a burning problem. Atg22p, an ignored integral membrane protein located in vacuole belongs to autophagy-related genes family; prior study recently reported that it is required for autophagic degradation and efflux of amino acids from vacuole to cytoplasm. It may alleviate the intracellular starvation of nutrition caused by Ac and increase cell tolerance. Therefore, we investigate the role of atg22 in cell death process induced by Ac in which attempt is made to discover new perspectives for better understanding of the mechanisms behind tolerance and more robust industrial strain construction.

Results: In this study, we compared cell growth, physiological changes in the absence and presence of Atg22p under Ac exposure conditions. It is observed that disruption and overexpression of Atg22p delays and enhances acetic acid-induced PCD, respectively. The deletion of Atg22p in S. cerevisiae maintains cell wall integrity, and protects cytomembrane integrity, fluidity and permeability upon Ac stress by changing cytomembrane phospholipids, sterols and fatty acids. More interestingly, atg22 deletion increases intracellular amino acids to aid yeast cells for tackling amino acid starvation and intracellular acidification. Further, atg22 deletion upregulates series of stress response genes expression such as heat shock protein family, cell wall integrity and autophagy.

Conclusions: The findings show that Atg22p possessed the new function related to cell resistance to Ac. This may help us have a deeper understanding of PCD induced by Ac and provide a new strategy to improve Ac resistance in designing industrial yeast strains for bioethanol production during lignocellulosic biofuel fermentation.
\end{abstract}

Keywords: Saccharomyces cerevisiae, atg22, Acetic acid, Programmed cell death, Amino acid transport, Cell wall and cytomembrane

*Correspondence: wzhang235@gmail.com; chenqh@zju.edu.cn

†ingjin Hu and Yachen Dong contributed equally to this manuscript

1 Department of Food Science and Nutrition, Key Laboratory for Food

Microbial Technology of Zhejiang Province, Zhejiang University, Hangzhou 310058, China

${ }^{2}$ Department of Cardiovascular \& Metabolic Sciences, The Lerner Research Institute, Cleveland Clinic, Cleveland, OH, USA

Full list of author information is available at the end of the article

\section{Background}

Growing exhaustion of fossil fuel and increasing deterioration of environment shine a spotlight on cellulosic ethanol which is regarded as the most promising substitute of petrochemical resources for their abundant, available, low-cost feedstocks from forestry residues, agricultural residues and energy crops $[1,2]$. However, toxic compounds such as weak acid, furans, phenolic compounds, and hydroxymethylfurfural (HMF), which were produced during lignocellulose-based saccharification and 
fermentation process, inhibited cell growth of Saccharomyces cerevisiae, the optimal microorganism of bioethanol manufacture, and declined bioethanol productivity [3]. Among all threatening inhibitors, acetic acid (Ac), the most abundant and harmful by-product in lignocellulosic hydrolysates, can inhibit cell growth and decrease alcohol productivity by disrupting cell metabolism such as intracellular acidification [4], oxidative stress and ATP depletion, inhibiting glycolytic process, suppressing amino acids uptake, impairing plasma membrane stability and selective permeability, decreasing cell wall integrity and organization, and degrading mitochondrion. Ultimately, Ac induced programmed cell death (PCD) of Saccharomyces cerevisiae $[5,6]$. To increase Ac tolerance in yeast cells, numerous works including overexpression or deletion of single gene, manipulation of Haa1-Regulon, evolutionary engineering and genome shuffling, transcriptome remodeling and supplementation of growth media with cations were explored and delightful results were achieved [4, 7-9]. We also have shown that numerous amino acid permeases, transporters and critical proteins responsible for uptake and synthesis of amino acids are transcriptionally repressed by Ac using a RNA-Seq-based analysis and evidences from previous study showed Ac can inhibits the uptake of histidine, lysine, uracil, tryptophan, glucose, and phosphate [5, 6, 10-13]. Nonetheless, further in-depth research is indispensable for understanding the mechanisms of stress tolerance, and implementing efficient and economical strategies that used $S$. cerevisiae as microbial factories to fabricate bioethanol.

In $S$. cerevisiae, the maximal tolerance to Ac is dependent on a persistent and efficient capacity for acquiring available amino acids to maintain a basic physiological function [10, 14]. Accordingly, modulation of amino acid metabolic pools likely contributes to improve the survivability of $S$. cerevisiae upon Ac treatment. Atg22p, an obscure member of autophagyrelated genes (Atg) family, is localized on the vacuolar membrane, and consisted of 528 amino acids which constitute 12 transmembrane helices with limited homologies to permeases [15]. Compared to other well-known autophagy-related genes such as atg1, atg8 or $\operatorname{atg} 5, \operatorname{atg} 22$ was unnecessary for autophagy and paid little attention to. Initially, it was deemed that atg22 plays a vital role in cooperating with aut4 during the last step of autophagy-autophagic bodies breaking down within lysosome/vacuole, for the slight accumulation of autophagic bodies emerged inside the vacuole because Atg22 $/$ Aut $4 \Delta$ mutant cells under starving situation. However, further study revealed this function was not direct or crucial. Atg22 $\Delta$ may delay autophagic bodies breakdown kinetically rather than lead autophagy-defective. Furthermore, atg22 is proposed to be related with amino acids recycled from vacuole to cytosol after autophagic bodies degradation, that is a critical part of autophagy performing its function as an internal nutrient pool to maintain the indispensable metabolism of cells and make them survive in extreme conditions. Specifically, atg22 is more likely to act as an effluxer mediating amino acids between vacuolar and cytosol by coordinating with another two-membrane proteins-avt3 and avt4, which have similar structure and identical location to atg22. Previous studies indicate that $\operatorname{Atg} 22 \Delta$ can damage the uptake ability of several amino acids such as lysine, histidine and arginine. Though direct evidences of atg22 acting as transporter of amino acid on vacuolar have not yet obtained, there is no doubt that Atg22p should go hand in hand with amino acid metabolism while it is never associated with Ac tolerance. These findings suggest new insights into how Atg22p regulates yeast cells response to Ac stress, and contributes to the exploration of the engineered S. cerevisiae strains with high inhibitors tolerance.

In this work, the phenotypic characterization of PCD upon Ac treatment was firstly compared between the Atg22 $\Delta$ mutant and wild-type BY4742. The effect of overexpression of atg22 gene on PCD under Ac stress was evaluated. Subsequently, the external and internal structure of $S$. cerevisiae mutant was observed by scanning and transmission electronmicroscopies. Further, compositions of cell wall and cytomembrane as well as the profiles of intracellular and vacuolar amino acids in S. cerevisiae cells were comparatively analyzed. Finally, reverse transcription quantitative real-time PCR (RTqPCR) was employed to investigate the transcriptional regulation of stress responses and cellular metabolism by $\operatorname{atg} 22$ disruption upon Ac treatment.

\section{Results}

\section{Atg22 deletion has a pro-survival role during acetic acid treatment}

In order to assess the effects of acetic acid on cell growth and viability, the growth curves were obtained by measuring $\mathrm{OD}_{600}$, and cell viability was tested by counting colony-forming units. We observed that both the wild-type (WT) and $\operatorname{Atg} 22 \Delta$ mutant were significantly growth-arrested by acetic acid stress (Fig. 1a), in accordance with the previous research [16]. The mutant showed a slower cell growth than WT in synthetic complete medium (SC) without acetic acid (CK), but Atg22 cells seemed to be growing more quickly than BY4742 until about $10 \mathrm{~h}$ after acetic acid (Ac) treatment, which was presented in the insert picture. Compared with the WT strain, there was an increase in cell survival of $A \operatorname{tg} 22 \Delta$ after treatment with different 

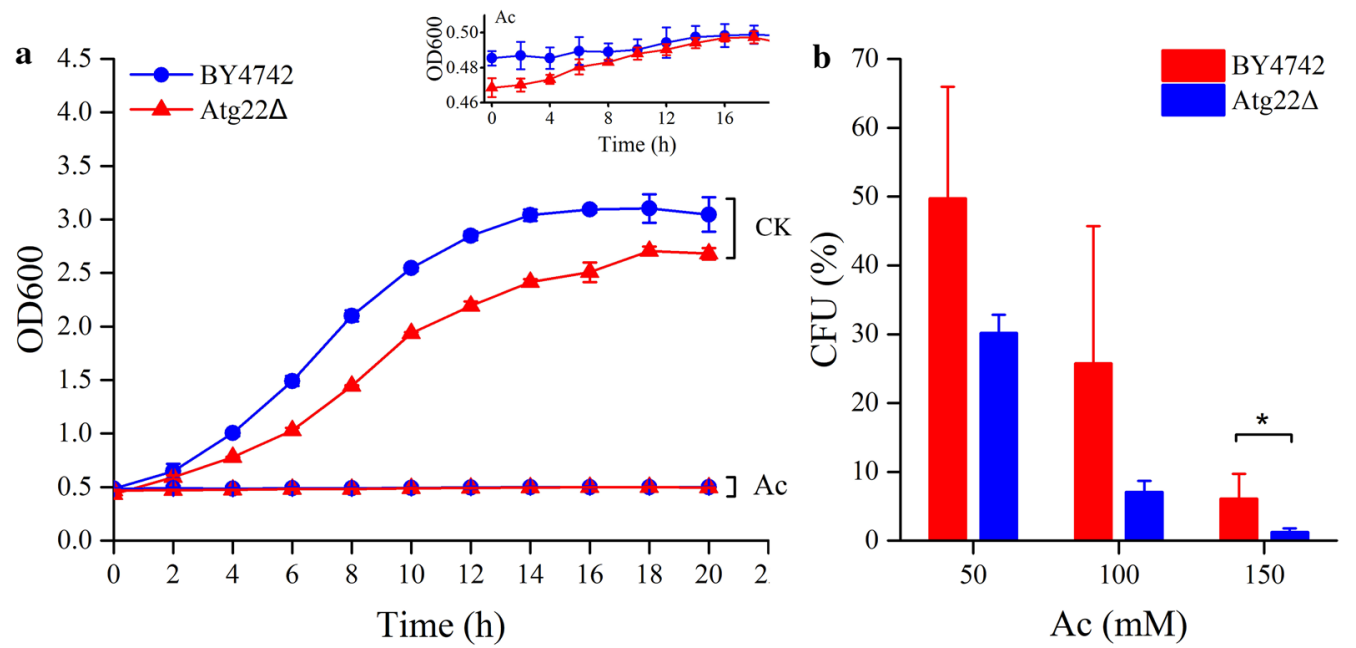

Fig. 1 Growth curves of S. cerevisiae BY4742 and Atg22 $\triangle(\mathbf{a})$, and cell survival of both strains after acetic acid treatment (b). The strains were cultured in SC media (pH 3.0) with acetic acid (Ac) or without $150 \mathrm{mM} \mathrm{Ac} \mathrm{(CK),} \mathrm{and} \mathrm{cultures} \mathrm{at} \mathrm{different} \mathrm{times} \mathrm{were} \mathrm{assayed} \mathrm{by} \mathrm{optical} \mathrm{density} \mathrm{at} 600 \mathrm{~nm}$ $\left(\mathrm{OD}_{600}\right)(\mathbf{a})$. An enlarged image of growth curve during acetic acid treatment is illustrated in the insert. Viability of yeast cells treated with different concentration of acetic acid for $2 \mathrm{~h}$ were determined by assaying colony-forming units (CFU) after 3 days cultivation on YPD agar plates (b). The data represent mean $\pm \mathrm{SD}\left(n=3 ;{ }^{*} P<0.05\right)$

concentrations of Ac (Fig. 1b). These findings indicated that the deletion of $\operatorname{atg} 22$ had a pro-survival role under acetic acid stress.

\section{Atg22 deletion results in inhibition of acetic acid-induced cell death}

Yeast cells undergoing cell death induced by Ac exhibit specific markers of apoptosis [17]. In order to elucidate the role of Atg22p in cell apoptotic process induced by Ac, several apoptotic markers were analyzed for $\operatorname{Atg} 22 \Delta$ and BY4742 cells under Ac treatment. We first assessed externalization of phosphatidylserine in the plasma membrane, a hallmark of apoptotic cells, which was assayed by a fluorescent conjugate of Annexin V-FITC. Simultaneously, we evaluated disruption of membrane integrity, a typical feature of necrosis and late apoptosis, by monitoring red fluorescence stained with propidium iodide (PI). Annexin V/PI costaining showed that Ac induced a continuous rise in exposure to phosphatidylserine and loss of plasma membrane integrity in both the control and mutant strains (Fig. 2a). The deletion of atg22 markedly reduced Ac-induced PCD as compared to the control after 120 and 200 min treatment. Obviously, yeast cells mainly show a late apoptosis-like phenotype under the designed condition at the stress of high Ac. Deletion of $\operatorname{atg} 22$ would reduce the sensitivity to Ac stress in S. cerevisiae. The falling mortality was accompanied by a rapid decline in the production of reactive oxygen species (ROS) (Fig. 2b) and striking increase in mitochondrial membrane potential at different times (Fig. 2c).

\section{Overexpression of Atg22p enhances cell death induced by Ac}

To assay the role of Atg22p in response to Ac, we compared the expression of atg22 under the control of an inducible and a constitutive promoter, respectively (Additional file 1: Figure S1). The plasmid pESC-Atg22 was constructed by sequences coding a homologous recombination atg22 with an inducible promoter GAL10. The BY4742 strain transformed with pESC-Atg22 was induced to express Atg22p in synthetic complete medium with $2 \%(\mathrm{w} / \mathrm{v})$ galactose $(\mathrm{SG})$ instead of $\mathrm{D}$-glucose. As shown in Fig. 3a, ectopic overexpression of Atg22p significantly accelerated the late apoptosis and necrosis induced by $150 \mathrm{mM}$ acetic acid, with the aggravated phenotype of phosphatidylserine externalization and loss of plasma membrane integrity. Upon Ac treatment, Atg22p overexpression significantly decreased cell viability.

Next, Atg22p was overexpressed in BY4742 cells under the control of a constitutive TEF2 promoter, and visualized by tracing a plasmid-based fusion protein consisting of EGFP fused at the C-terminus of Atg22p. The integrity of plasma membrane was firstly detected by PI staining for evaluation of cell death in yeast cells expressing Atg22p-EGFP and empty vector control (pTEF2). Consistent with the strain overexpressing Atg22p under an inducible promoter (BY-pESC-Atg22), cell death was significantly enhanced in $S$. cerevisiae cells harboring pTEF-Atg22-EGFP under Ac stress (Fig. 3b). Although pTEF-Atg22-EGFP was transformed into BY4742, not all cells were positive for GFP. The percentage of dead cells 


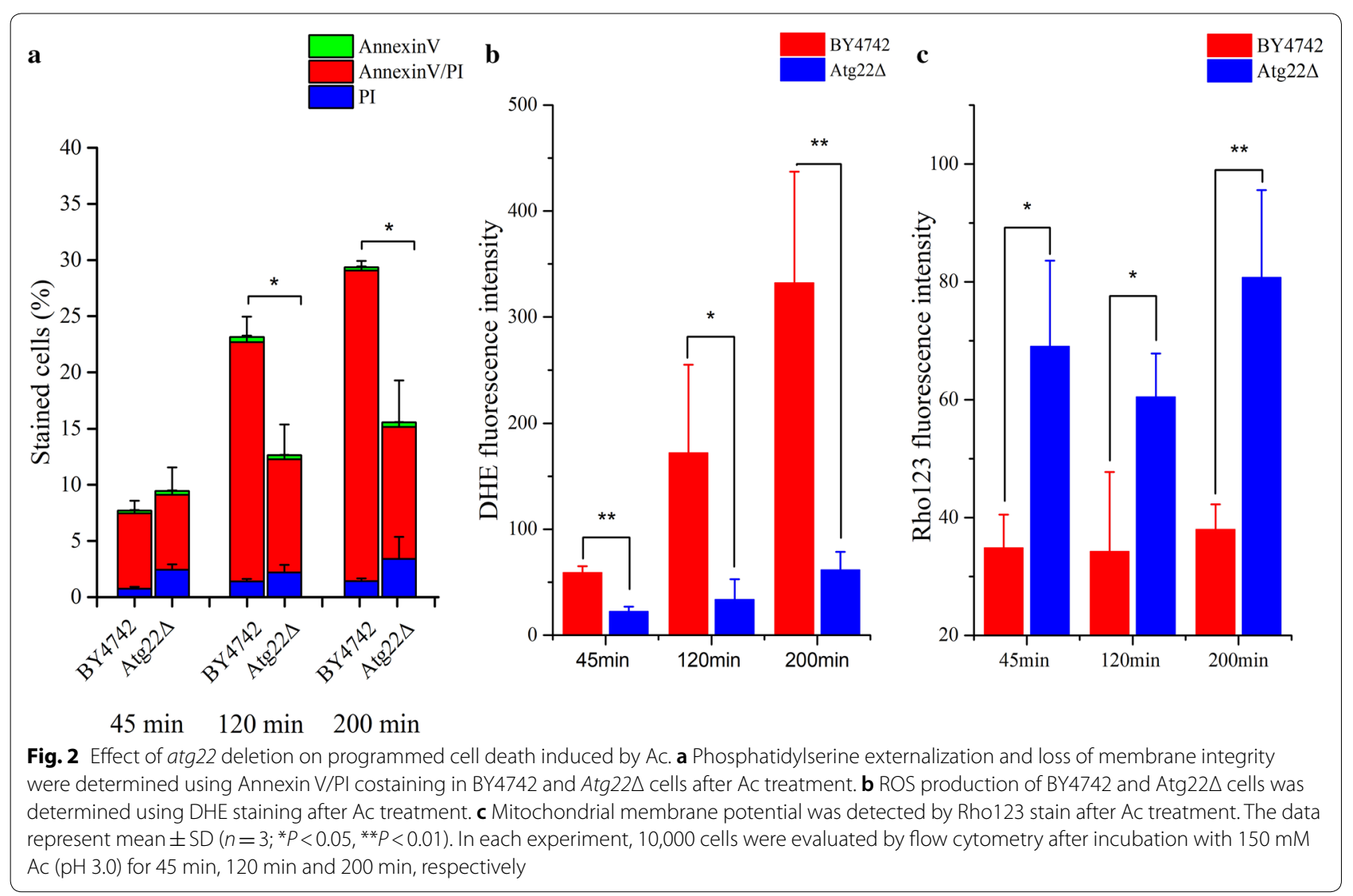

in GFP-positive cells was markedly higher than control cells transformed with the empty vector during acetic acid treatment at 45 and $120 \mathrm{~min}$. Interestingly, the former was also significantly higher than the whole cells carrying the plasmid pTEF-Atg22-EGFP at $45 \mathrm{~min}$. It was clear that overexpression of Atg22p impaired the survival of yeast cells in response to Ac.

The GFP-positive cells and mean fluorescence intensity (MFI) fell dramatically in all cells harboring pTEF-Atg22EGFP in the presence of Ac (Fig. 4a). Figure 4b shows that Atg22p mainly located in the vacuolar membrane. A high fluorescence intensity was observed in cells cultured in SC medium without Ac treatment. Confocal microscopy images confirmed that MFI was significantly decreased upon Ac stress in cells expressing Atg22-EGFP fusion protein. Simultaneously, there was a significant reduction of GFP-positive cells after Ac treatment (Fig. 4c), which was consistent with the above data measured by flow cytometry. Interestingly, the GFP-positive cells showed a higher cell death rate (white arrow) than the whole cells treated with acetic acid for $120 \mathrm{~min}$. Taken together, the levels of Atg22 may determine the sensitivity of yeast cells in response to Ac-induced apoptosis.

\section{Atg22 changes cell morphology under Ac treatment and regulates cell wall composition}

Cell wall generally signaled outer environmental stressors. To understand the role of atg22 affecting the change of cell wall under acetic acid, we adopted scanning electron microscopy (SEM) and transmission electron microscopy (TEM) to observe the surface and interior structure of $S$. cerevisiae under Ac and without treatment, respectively. In our previous study, Ac erosion made cells vulnerable and weak by thinning cell wall, abolishing lipid droplets accumulation, disintegrating organelles and increasing cytoplasm vacuolation. We compared the cell status of BY4742-pESC-ura, Atg22 $\Delta$-pESC-ura and BY4742-pESC-Atg22. Clearly presented, more fragments and wrinkles were observed on the surface of BY4741 and Atg22 overexpression strains (Fig. 5a). What's more, TEM observation reveals atg22 existence or overexpression may exacerbate the destruction of interior structure significantly. Additionally, the breakdown in atg22 deletion strain was partly compared with the extensive and exhaustive collapsing emerged in BY4742-pESC-ura and BY4742-pESC-Atg22 (Fig. 5b). To explore the reason behind this phenomenon, we analyzed cell wall components. The content of total polysaccharide 
a
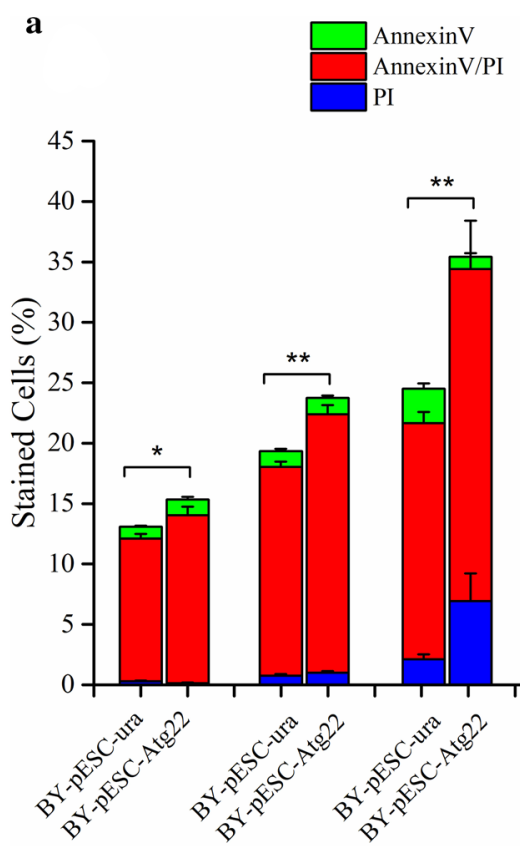

$45 \mathrm{~min} \quad 120 \mathrm{~min} \quad 200 \mathrm{~min}$

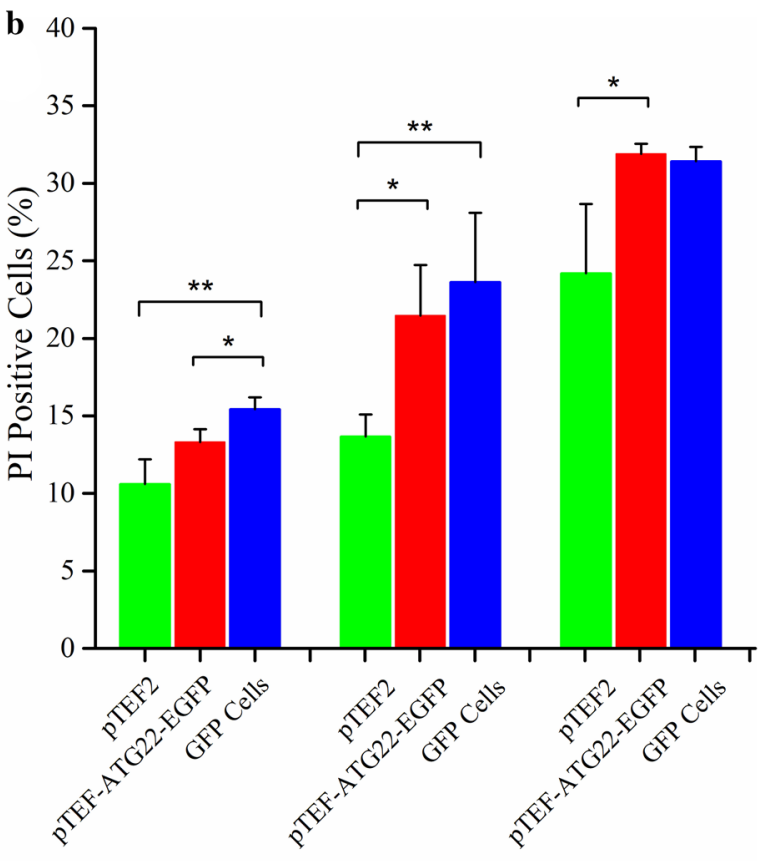

$45 \mathrm{~min}$

$120 \mathrm{~min}$

$200 \mathrm{~min}$

Fig. 3 Effect of atg22 overexpression on programmed cell death induced by acetic acid. a Phosphatidylserine externalization and loss of membrane integrity were determined using Annexin V/PI costaining in BY4742 cells harboring pESC-ura (BY-pESC-ura) or pESC-Atg22 (BY-pESC-Atg22) after acetic acid treatment. b Loss of membrane integrity was determined using PI staining in BY4742 cells harboring pTEF2 or PTEF-ATG22-EGFP after acetic acid treatment. The data represent mean $\pm \operatorname{SD}\left(n=3 ;{ }^{*} P<0.05,{ }^{* *} P<0.01\right)$. Cells were incubated with $150 \mathrm{mM}$ acetic acid for $45 \mathrm{~min}, 120 \mathrm{~min}$ and $200 \mathrm{~min}$, respectively. In each experiment, 10,000 cells were then evaluated by flow cytometry. GFP cells represent the BY4742 strain harboring pTEF-ATG22-EGFP with a positive Atg22p-EGFP fluorescence by flow cytometry

is $37.8 \%$ lower under control situation as compared to BY4742-pESC-ura, while 5\% higher after $150 \mathrm{mM}$ Ac exposure. Moreover, Ac treatment decreased $38.6 \%$ and $37.8 \%$ of total polysaccharide in control strain and overexpression strain restrictively, but had no influence on $\operatorname{Atg} 22 \Delta$ strain (Fig. 6a). In the control group, atg22 deletion resulted in the loss of amounts of glucan, mannan and chitin by $27.5 \%, 37.4 \%$ and $27.7 \%$, respectively. Upon $150 \mathrm{mM}$ Ac treatment, those constituents decreased by $22 \%, 34.8 \%, 32.8 \%$ in BY4742-pESC-ura and $22.7 \%$, $32.4 \%$, 36.1\% in BY4742-pESC-Atg22, respectively, in contrast to the control. Interestingly, glucan was the only one of polysaccharides upregulated in $\operatorname{Atg} 22 \Delta$, indicating atg22 affects cell wall compositions synthesis (Fig. 6b-d).

\section{Atg22 regulates plasma membrane rigidity and compositions}

Fluorescence polarization results revealed that cell membrane rigidity was $8.7 \%$ higher in the $\operatorname{Atg} 22 \Delta$ strain than in the wild-type one but that the level in the atg22 overexpression strain was similar to the wild-type strain without Ac treatment. However, Ac caused cell membrane rigidity to decrease by $39.2 \%, 40.4 \%, 43.2 \%$ in BY4742-pESC-ura, Atg22 - -pESC-ura and BY4742pESC-Atg22, respectively. However, cell membrane rigidity in atg22 deletion strain showed 6\% and $12.7 \%$ higher than the control and the overexpression strain, respectively (Fig. 7a). We compared the membrane components among three strains. Upon Ac exposure, the total content of fatty acid, saturated fatty acids, and unsaturated fatty acids decreased by $39 \%, 20 \%$ and $44 \%$ in BY4742-pESC-ura; reduced 22\%, increased $20 \%$, reduced $21 \%$ in $\operatorname{Atg} 22 \Delta$ strain; upregulated 33\%, $80 \%$, $21 \%$ in overexpression strain. Under control conditions, total content of fatty acid in Atg22 $\Delta$ was $25 \%$ and $64 \%$ higher than control and overexpression strain; total content of saturated fatty acid in $\operatorname{Atg} 22 \Delta$ was $28 \%$ and $72 \%$ higher than control and overexpression strain; $18 \%$ and $70 \%$ higher than control and overexpression strain in total content of unsaturated fatty acid (Fig. $7 \mathrm{~d}-\mathrm{f}$, Additional file 1: Table S1). The content of myristic acid, palmitic acid, stearic acid, lignoceric acid, palmitoleic acid, oleic acid, cis-4,7,10,13,16,19-docosahexaenoic acid in $\operatorname{Atg} 22 \Delta$ is more enriched than that in wild-type and 


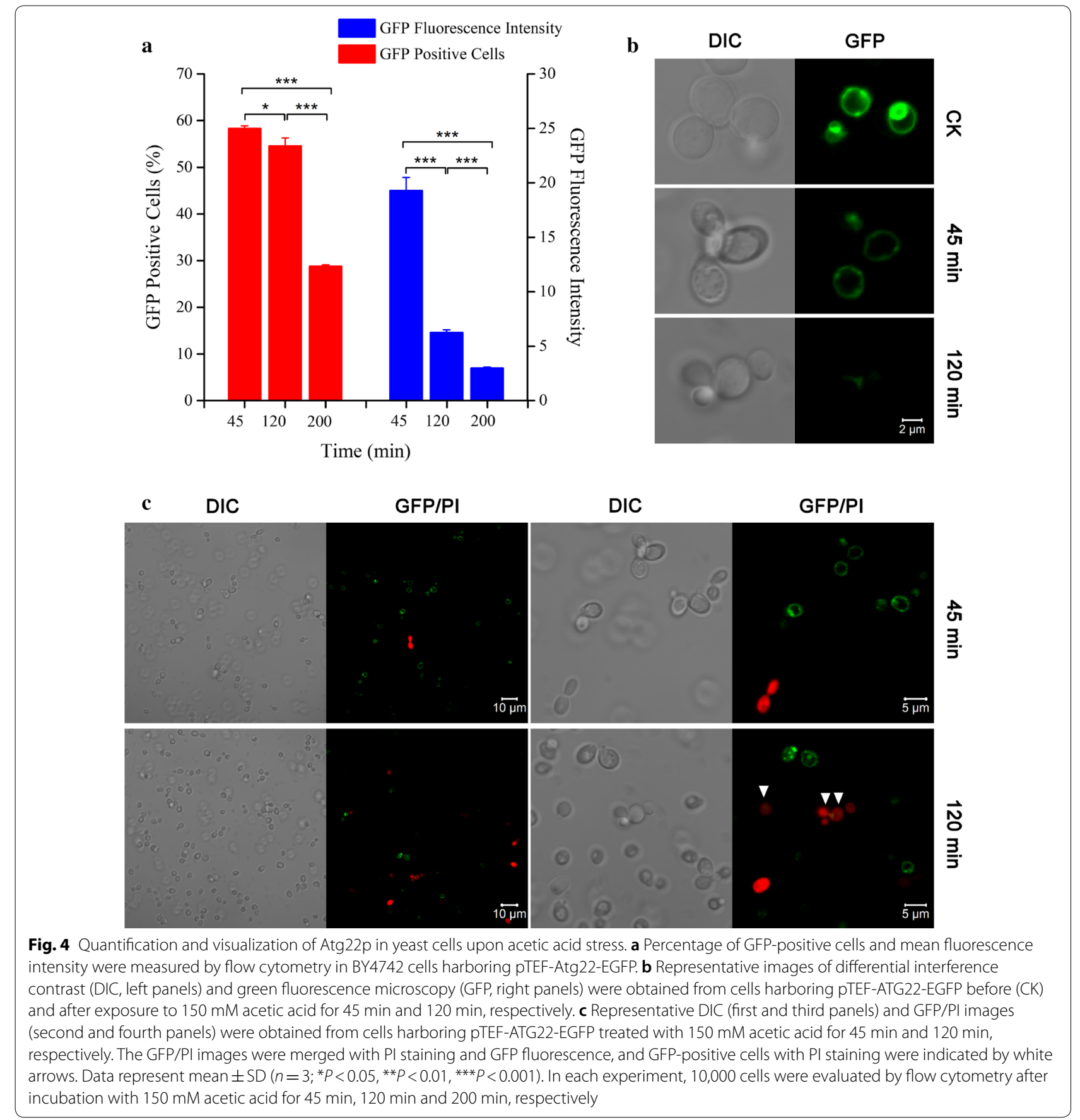

overexpression groups. The total content of fatty acid in $\operatorname{Atg} 22 \Delta$ was $58 \%$ higher than the control strain (Fig. $7 d$ ); total content of saturated fatty acids in $\operatorname{Atg} 22 \Delta 92 \%$ and $14 \%$ higher than the control and overexpression strain, respectively; $66 \%$ and $11 \%$ higher than control and overexpression strain in total content of unsaturated fatty acids (Fig. 7e, f). The content of myristic acid, palmitic acid, stearic acid, lignoceric acid, palmitoleic acid, elaidic acid, oleic acid, cis-4,7,10,13,16,19-docosahexaenoic acid in $\operatorname{Atg} 22 \Delta$ strain is $2.87,1.31,1.54,5.14,1.52$, 1.87, 1.21, 2.76-fold of BY4742-pESC-ura and 1.48, 0.96, $1.07,1.51,1.04,1.36,1.2,1.19$-fold of the overexpression strain (Fig. 8a-h). Further, membrane sterol levels were investigated to determine whether atg22 affects sterol biosynthesis. The content of sterols was presented in Additional file 1: Table S2, and we found that the deletion 


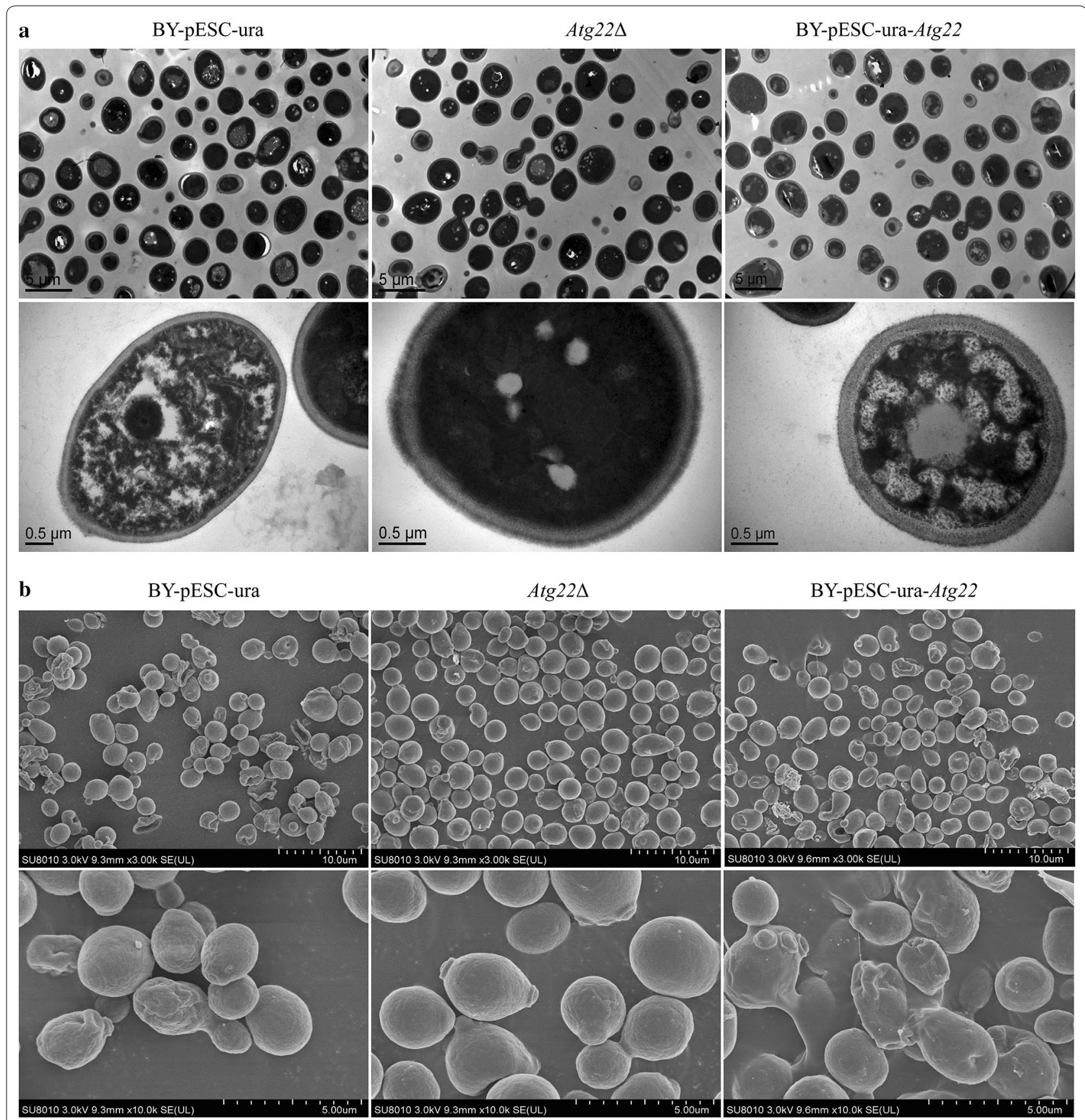

Fig. 5 Morphology changes under $150 \mathrm{Mm}$ Ac for 120 min treatment. a Interior structure changes observed by TEM. b Surface structure changes detected by SEM. All cells exposed to $150 \mathrm{Mm}$ Ac for $120 \mathrm{~min}$, and every and biological triplicate were performed

of atg22 upregulated the levels of squalene. No change was observed in $\operatorname{atg} 22$ overexpression strain except $10 \%$ decrease of squalene. At $150 \mathrm{mM}$ Ac, in BY4742-pESCura only 4,4-dimethylzymosterol increased 7\% compared with the control. In $\operatorname{Atg} 22 \Delta$, squalene and zymosterol decreased by $12 \%, 8 \%$, respectively. The findings implied that overexpression of atg22 increased the levels of sterols except for ergosterol (Fig. 9a-f).

Next, the content of phospholipids in cell membrane was comparatively analyzed (Fig. 10a-f). We found the total concentrations decreased by $7 \%$ and $6.6 \%$ in $\operatorname{atg} 22$ deletion and overexpression strains, respectively (Additional file 1: Table S3). Without Ac 


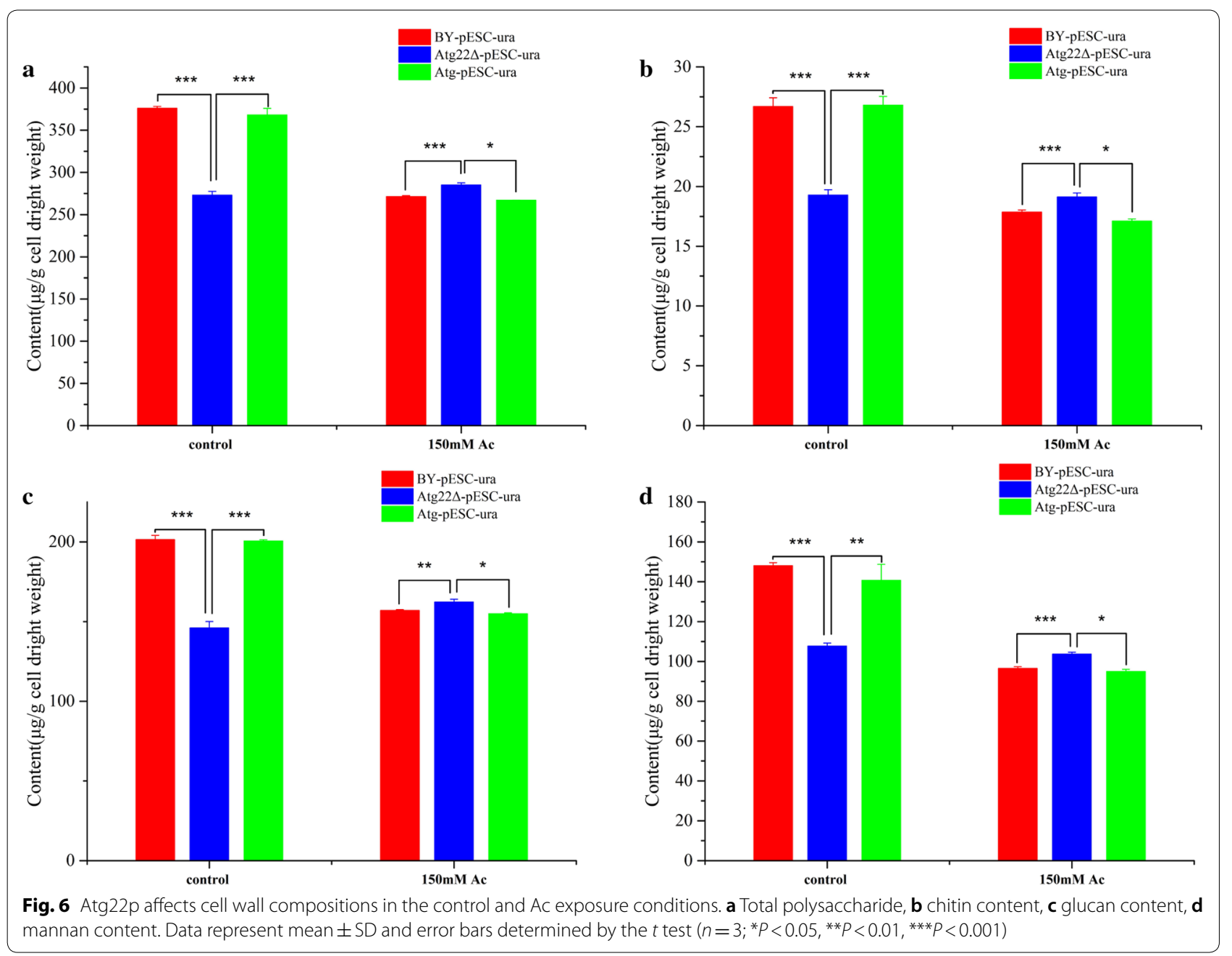

treatment, phosphatidic acid (PA), phosphatidylserine (PS) increased by $341 \%, 22 \%$ and phosphatidylglycerol (PG), phosphocholine (PC), phosphatidylinositol (PI) decreased by $51 \%, 9 \%, 13 \%$ in Atg $22 \Delta$ strain, respectively. In atg 22 overexpression strain, PA, PC, phosphatidylethanolamine (PE), PI down by $9 \%, 6 \%, 8 \%, 16 \%$ and PG, PS up by $14 \%, 11 \%$, respectively, compared with the control. At $150 \mathrm{mM}$ Ac, the total phospholipids increased 36\%, 43\%, 66\% in BY4742-pESC-ura, Atg22D and BY4742pESC-Atg22, respectively. Concretely, in BY4742pESC-ura strain PA, PE up by $164 \%, 175 \%$, respectively. Meanwhile, in $\operatorname{Atg} 22 \Delta$ strain, PG, PE increased by $317 \%$, $186 \%$ while PA and PS decreased by $31 \%, 5 \%$, respectively. In BY4742-pESC-Atg22 strain all component contents were upregulated in which PA, PG, PE, PI increased by $22 \%, 63 \%, 254 \%$, and $388 \%$, respectively. The present findings implied that vacuolar atg22 has directly regulated yeast cell death under Ac.

\section{The Atg22 $\Delta$ cells accumulate cytosolic amino acids} during Ac treatment

Vacuolar Atg22p is required for efflux of amino acids and breakdown of autophagic bodies [18]. The contents of total amino acids and vacuolar amino acids were measured for evaluating the effect of Atg22p deficiency on intracellular amino acid pools. As presented in Fig. 11a, wild-type BY4742 cells accumulated higher concentration of vacuolar amino acids compared with $\operatorname{Atg} 22 \Delta$ mutant, while there was insignificant difference in total amino acids between the two strains upon acetic acid treatment. The concentration of cytosolic amino acids in mutant was 2.2-fold higher than the WT strain $(P<0.001)$. Moreover, the cytosolic contents of threonine, glutamic acid, proline, glycine, methionine, leucine, lysine, and arginine were obviously increased by atg 22 mutation (Fig. 11b). Only the content of alanine in cytosol decreased significantly. Ac was reported to induce severe nutrient limitation in yeast $[5,6,10]$. These data suggest that Atg22p probably plays a distinct role 


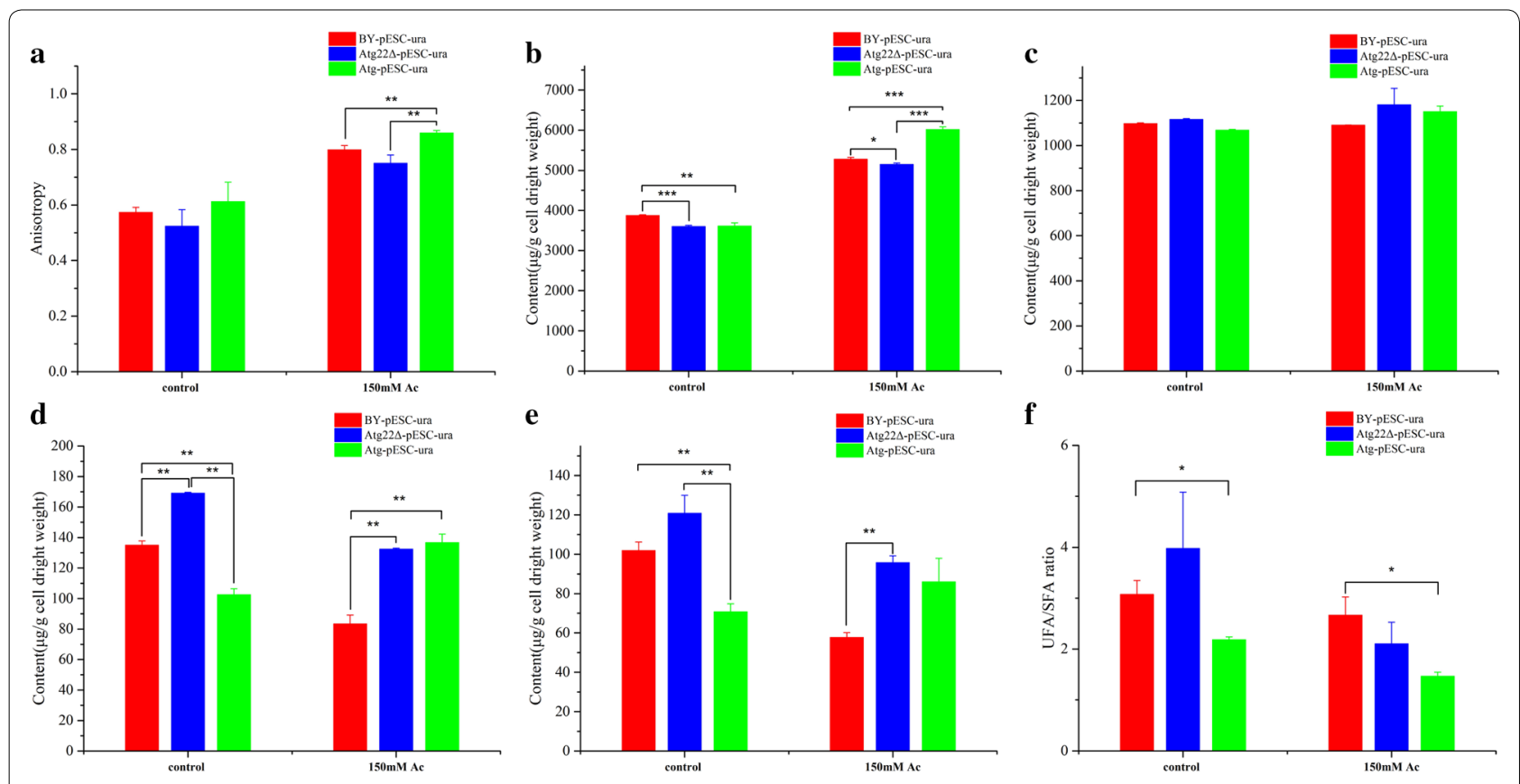

Fig. 7 Effect of atg22 on membrane rigidity and total compositions. a Assays of membrane rigidity, $\mathbf{b}$ total phospholipid, $\mathbf{c}$ total sterol, $\mathbf{d}$ total fatty acid, e total UFA, $\mathbf{f} \cup F A / S F A$. All experiments were implemented in biological triplicate. Data represent mean $\pm S D$ and error bars determined by the $t$ test $\left(n=3 ;{ }^{*} P<0.05,{ }^{* *} P<0.01,{ }^{* * *} P<0.001\right)$

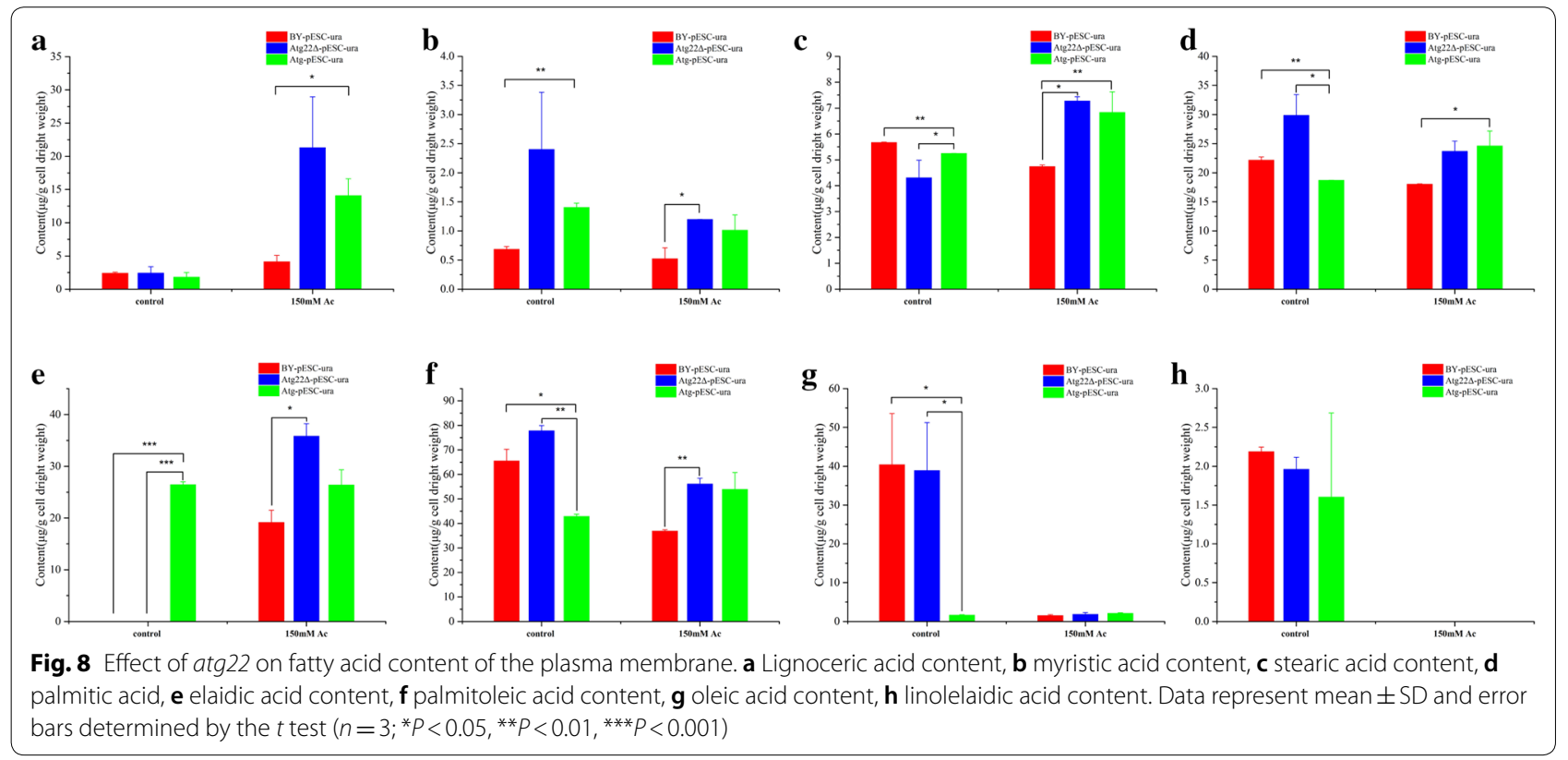

in regulation of amino acid pools between cytosol and vacuole upon Ac stress, and the deletion of atg22 leads to cytosolic accumulation of amino acids aiding yeast cells under amino acid starvation induced by Ac.
Deletion of $\operatorname{atg} 22$ promotes gene expression in heat shock protein family, cell wall integrity pathway and autophagy in response to Ac stress

In our previous study [2] and the relevant report [19], many differentially expressed genes were identified to be involved in stress responses and Ac-induced PCD 


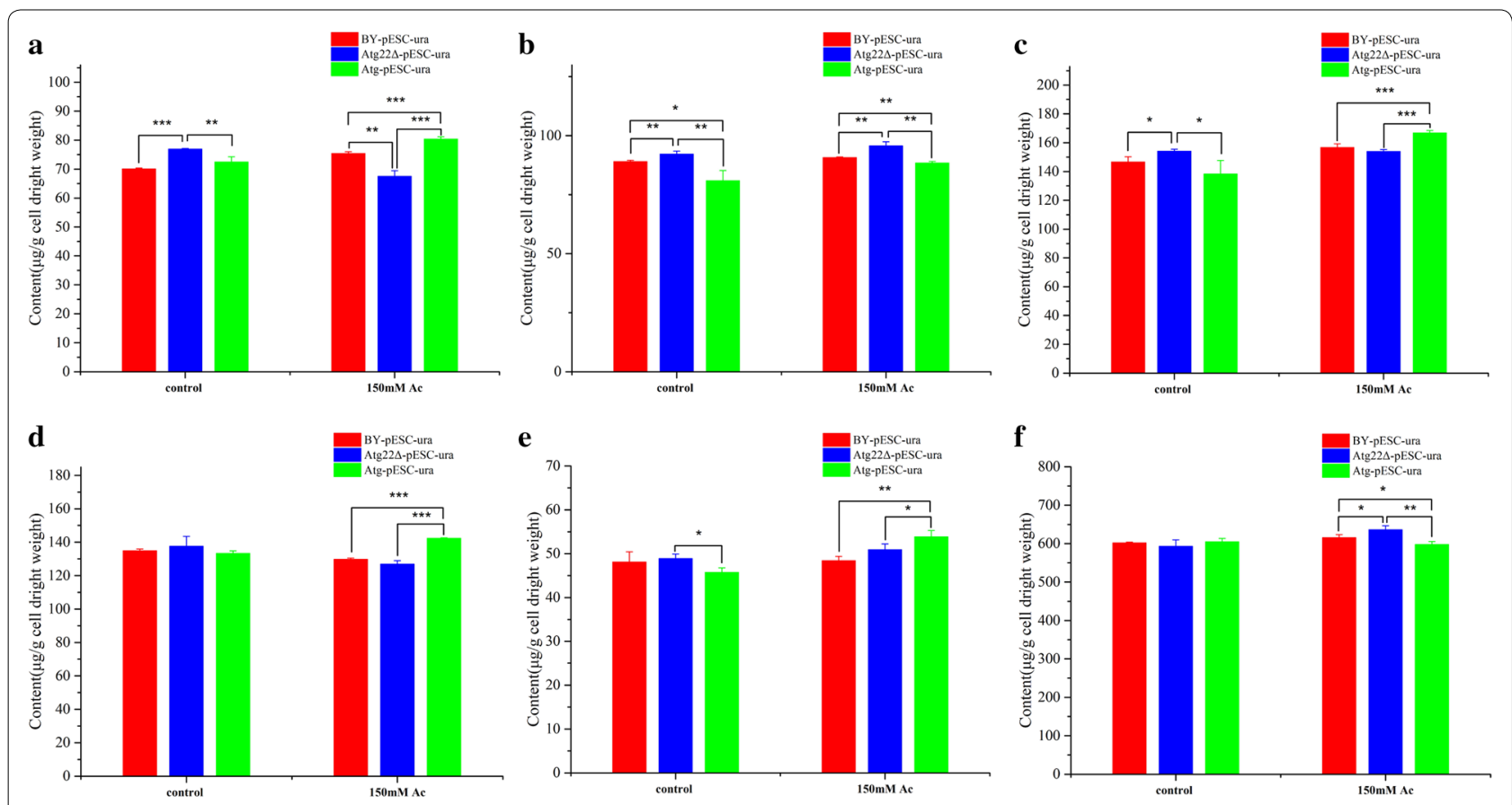

Fig. 9 Influence of atg22 on sterol content of the plasma membrane. a Squalene content, $\mathbf{b}$ lanosterol content, c 4,4-dimethylzymosterol content, d zymosterol content, e fecosterol content, $\mathbf{f}$ ergosterol content. Data represent mean \pm SD and error bars determined by the $t$ test $\left(n=3 ;{ }^{*} P<0.05\right.$, $\left.{ }^{* *} P<0.01,{ }^{* * *} P<0.001\right)$

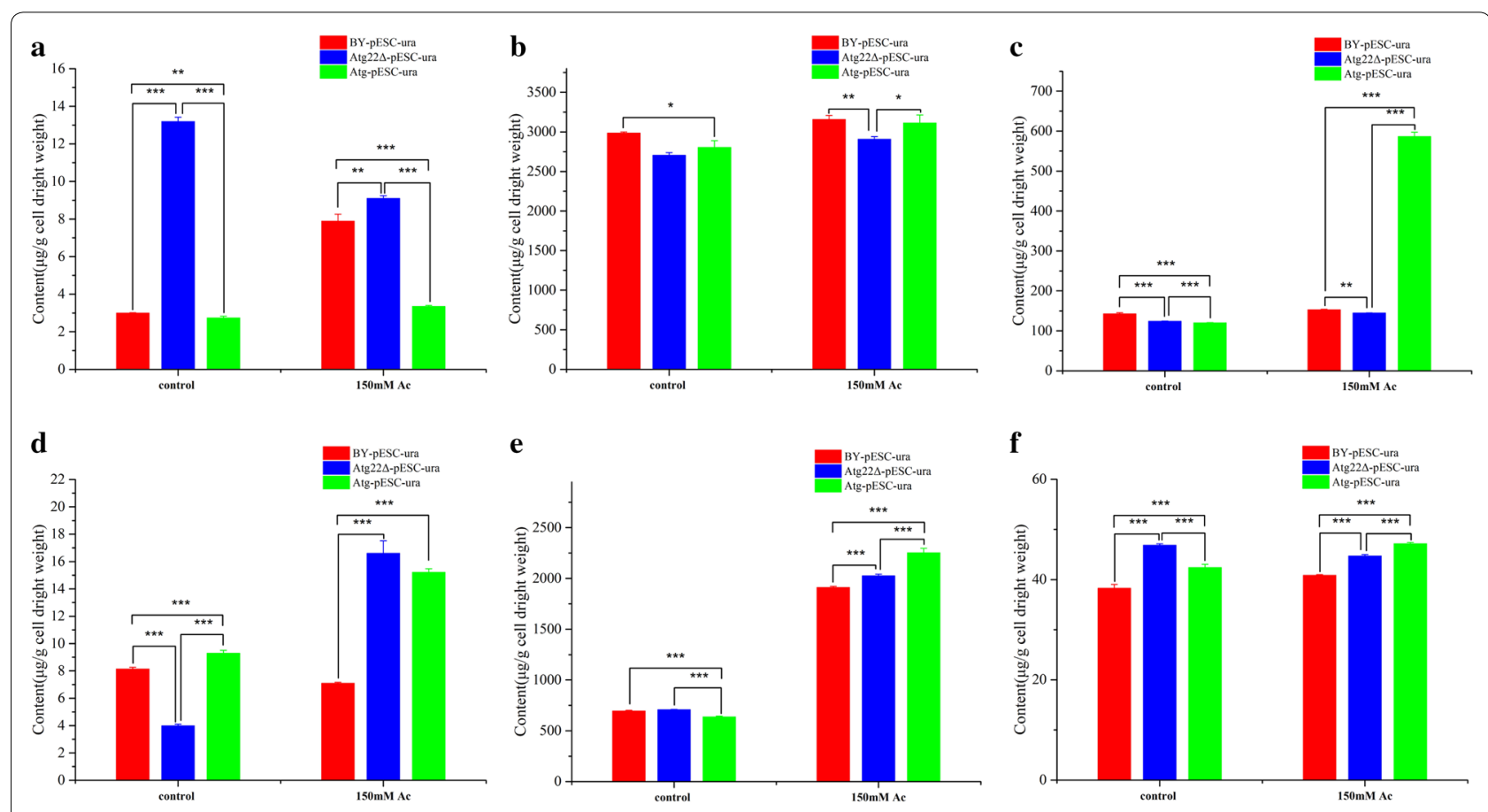

Fig. 10 Influence of atg22 on phospholipid content of the plasma membrane. a PA, b PC, $\mathbf{c} P$, $\mathbf{d} P G, \mathbf{e} P E, \mathbf{f} P S$. Data represent mean $\pm S D$ and error bars determined by the $t$ test $\left(n=3 ;{ }^{*} P<0.05,{ }^{* *} P<0.01,{ }^{* *} P<0.001\right)$ 

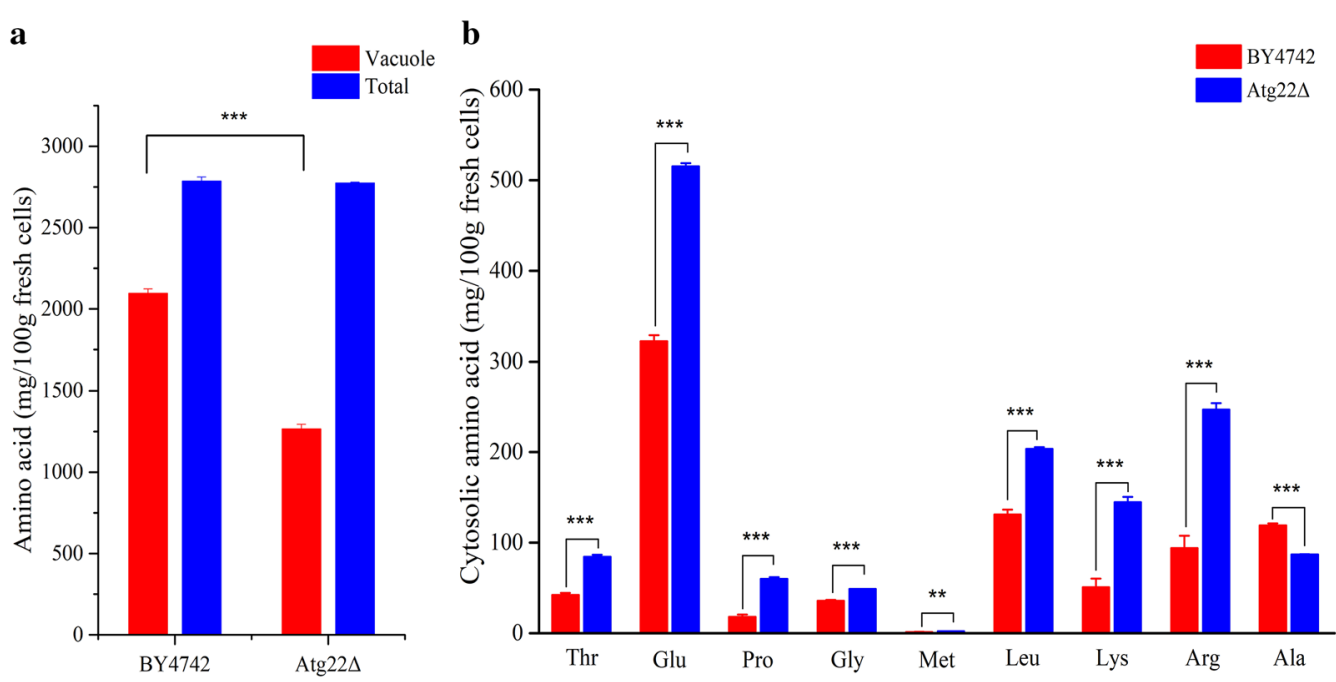

Fig. 11 Effect of atg22 deletion on intracellular amino acid pools during acetic acid treatment. a Vacuolar and total amino acid pools, b cytosolic concentrations of representative amino acids. The data represent three independent experiments and error bars determined by the $t$ test $\left({ }^{*} P<0.05\right.$, $\left.{ }^{*} P<0.01,{ }^{* * *} P<0.001\right)$

by RNA-Seq-based transcriptomic analysis. In this work, 51 key genes in related biological processes were as well selected to investigate the protective role of atg22 deletion against cell death induced by Ac using RT-qPCR. Upon Ac stress, the mRNA abundance of 20 genes showed a significant increase in Atg22 strain as compared with the wild-type BY4742 under the same culture conditions. The upregulated genes probably contributed to improve Ac tolerance in the mutant, mainly involved with heat shock protein family (ssa3, fes1, hsp30, ssa4, hsp82, hsp104, cpr6, hsc82, $s t i 1)$, cell wall integrity pathway (slt2, gsc2, $p k c 1$, tip1, rlm1), autophagy (atg8, atg12, atg2), vacuolar proteolysis (pep4), and other processes (rgi1, btn2). Especially, the mRNA levels of all the investigated genes encoding heat shock proteins in the mutant were significantly enhanced more than 1.5 -fold $(P<0.01)$ as compared with the control. However, there was insignificant change in transcription of all 11 genes involved in histone acetylation and deacetylation (Additional file 1: Table S4), indicating the cellular acetylation balance was not significantly changed by atg 22 deletion under Ac pressure. Hence, atg22 disruption activated intensively the transcription of genes encoding stress-related proteins to improve the survival upon Ac (Fig. 12).

\section{Discussion}

Multiple efforts have been made to improve Ac resistance and elucidated mechanisms of stress resistance in yeast $[4,20,21]$. However, little attention is paid to the relationship between Ac resistance and atg22, a small membrane-spanning protein on vacuole of $S$. cerevisiae. In this work, we discovered the function of atg22 in the PCD induced by Ac through affecting cell wall synthesis, cell membrane structure and function, and amino acids transport between cytosol and vacuole, stress genes expression with regards to HSP family, Atg family and CWI, the postulated regulation pathway shown in Fig. 13. These findings emphasize the communication role of vacuolar Atg22p involved in the PCD under stress factors.

\section{Programmed cell death triggered}

Interestingly, the Atg22 $\Delta$ mutant presents better survivability in acetic acid-containing medium compared with WT strain and atg22 overexpression one. By contrast, overexpression of $\operatorname{atg} 22$ enhanced acetic acid-induced cell death, and the increased intracellular degradation of proteins and organelles in this process led to a sharp decline in proportion and mean fluorescence intensity of GFP-positive cells. This result was proved by the observation of Annexin V/PI showing atg22 deletion alleviated PCD and the overexpression strain aggravated. In turn, Ac induced the degradation of Atg22p. Reactive oxygen species (ROS) accumulation and mitochondria degradation were also involved in Ac-induced apoptosis $[17,22]$. ROS production during cell metabolism by mitochondrial electron transport chain or non-mitochondrial pathway is beneficial to signal transmission [23]. However, the elevated accumulation of ROS triggered by Ac cause lipid peroxidation, protein oxidation, vacuolar acidification, genetic damage and sphingolipids 


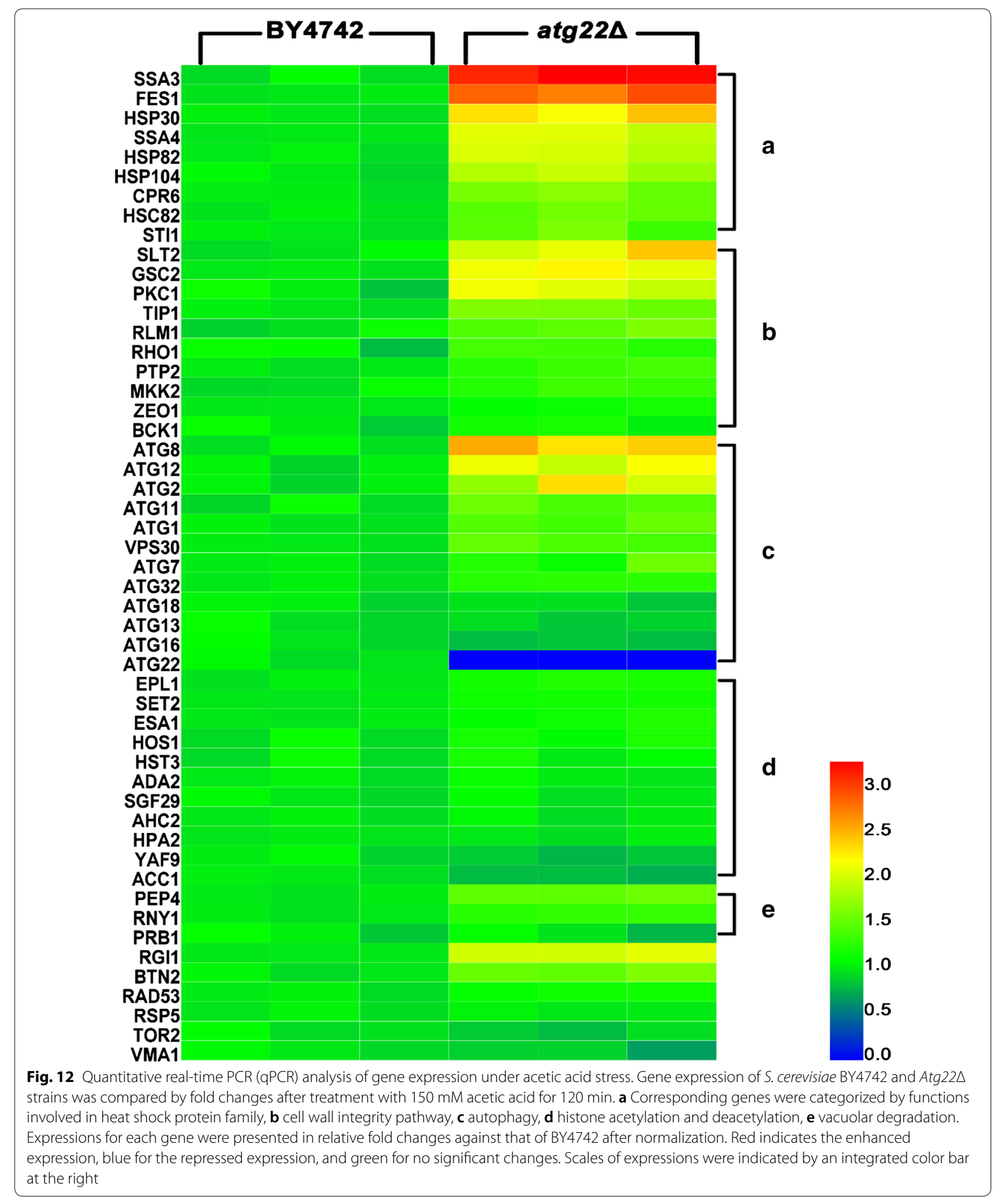




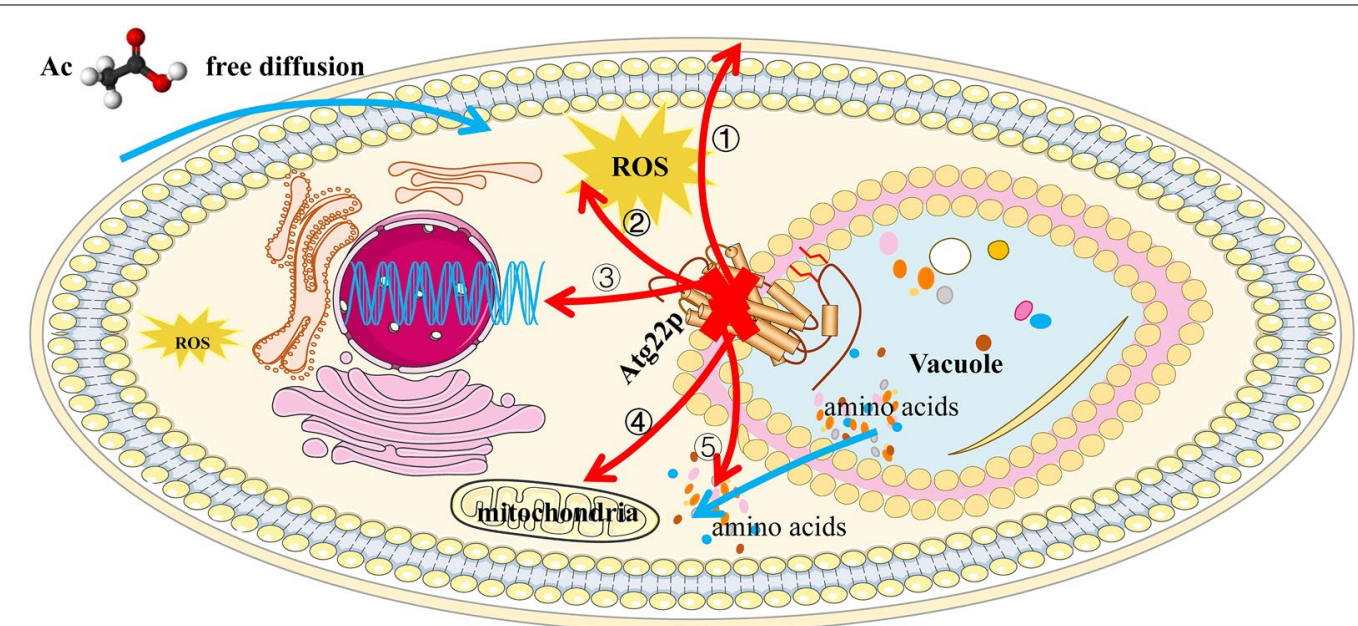

Fig. 13 Schematic diagram of Atg22 deficiency contributes to reduce programmed cell death induced by acetic acid in Saccharomyces cerevisiae. (1) Obstruction of Ac entrance by influencing compositions, function of cell wall and membrane. (2) Decreasing accumulation of ROS in cytoplasm. (3) Upregulation of genes expression in heat shock protein family, cell wall integrity pathway and autophagy. (4) Maintaining mitochondrial membrane potential. (5) Changing amino acids between vacuole and cytoplasm promotes amino acids flowing from vacuole to cytoplasm

decrease [24, 25]. Mitochondria by means of releasing cytochrome accomplished double mission of electron donation and ROS scavenging [26]. It is exhibited that less ROS production in the cytoplasm and higher mitochondrial membrane potential $(\Delta \Psi \mathrm{m})$ were detected in Atg22 $\Delta$ mutant. The data mean atg 22 absence might suppress ROS formation to protect the damage of mitochondria (Fig. 13). All of this attest to the fact that Atg22 $\Delta$ showed a better performance and superior survivability in the presence of Ac. In other words, deletion of atg22 gene in yeast contributes to reduce programmed cell death induced by acetic acid in S. cerevisiae.

\section{Cell wall compositions and integrity}

In budding yeast, cell wall was supposed as dynamic organelle that played vital role in the maintenance cell morphology, mechanical strength, proliferation and the first barrier to protect cell from extracellular environment pressure [27]. Our preceding research revealed that Ac treatment significantly repressed cell wall organization particularly glucan biosynthesis at mRNA level and resulted in cell wall thinner with a darker color [2]. However, in this study we found the cell wall of Atg22 $\Delta$ showed more integrity than BY4741 and overexpression strain after Ac treatment. Ac treatment sharply reduced cell wall composition of glucan, mannan and chitin in BY4741-pESC-ura and BY4741pESC-Atg22 while had no influence on Atg22 $\Delta$. Meanwhile, disruption of atg22 enhances transcription of key genes involved in cell wall integrity pathway (CWI pathway) (tip1, pkc1, slt2, rlm1, gsc2) which may provide protection to cells against acetic acid. Cell wall remodeling in response to acetic acid and other weak acids is essential to protect cells from damage $[28,29]$. Atg22 deletion not only prevents cell wall composition loss, but also upregulates key genes expression of CWI pathway which may lead cell wall that is robust and compact to withstand Ac uptake. On the other hand, glucan and chitin served as an exoskeleton and a scaffold linked to the external mannoproteins which is positively related with cell resistance of adversity such as sodium houttuyfonate and caspofungin, the increase of glucan synthase likely reduces susceptibility of Ac in $S$. cerevisiae [29-34].

\section{Cell membrane integrity, permeability and fluidity}

Cytomembrane is the permeability barrier which plays a vital role in information transfer, substance exchange and separation of cytoplasm and extracellular environment [35]. It is demonstrated that Ac enters into cytoplasm by diffusing across the cytomembrane and consequently disrupts $\mathrm{pH}$ homeostasis intensifying intracellular acidification which eventually induce PCD $[36,37]$. Preceding researches suggest that the integrity, fluidity, and permeability of cell membrane affected by its compositions and be closely linked with the uptake as well as resistance of Ac [38-41]. We manifested that Atg22p deficiency is favorable to strengthen membrane integrity, fluidity and permeability by means of changing compositions ultimately reducing PCD induced by Ac. Phospholipids is an important structure component of membrane lipid bilayer, and make sense for membrane 
fluidity and integrity. Researches showed that the upregulation of phospholipids level can help $S$. cerevisiae cells to adapt Ac toxicity and decrease ROS accumulation [24, 42]. In this investigation, total content was prominently upregulated by Ac treatment which might adaptively respond to Ac stress as previously reported [42, 43]. Concretely, atg22 deletion facilitated PG, PA accumulation while overexpression facilitated PS, PI and PE as exposed to Ac, respectively. PA is an indispensable intermediate in phospholipids metabolism and PG acts as a key fusion for two other phospholipids which may indicate that their sediment make for the decrease of membrane permeability to prevent cell from Ac diffusion [39, 42, 44, 45]. Increasing proportion of PS and PE may reduce unsaturation to impair membrane fluidity and hinder the coping with Ac exposure [40, 46]. Sterols play a crucial part in structure-function, microdomain formation, protein-lipid interactions and signal transduction [47, 48]. Sterols can increase membrane integrity by fortifying packing density and weakening acyl chain flexibility through interacting with phospholipids by which influence cell resistibility to stress [43, 49, 50]. Moreover, ergosterol is widely identified as the most important sterol associated with inhibiters resistance which can form transmembrane channel structures by interacting with some substrates and consequently boost membrane order subdued substrates permeability [51-55]. Ergosterol accumulation contributed to yeast cell survival under vanillin, ethanol, temperature, and $\mathrm{pH}$ stress contrasted with the disruption of ergosterol biosynthesis exacerbated the toxic effects of mono-(2-ethylhexyl)phthalate, lovastatin, nystatin, amphotericin B, and terbinafine [38, 56-61]. Ac increased ergosterol accumulation while decreased in zymosterol which were more significant in $\operatorname{Atg} 22 \Delta$ strain, but opposite in the overexpression strain. These data revealed that Atg22p absence promoted the transformation from zymosterol to ergosterol and amassing. Accumulation of squalene in BY4741-pESC-Atg22 strain also provided collateral evidence for atg22 overexpression blocked ergosterol biosynthesis which possibly damages membrane permeability and exacerbates PCD induced by Ac $[38,46]$.

Membrane fluidity shows positive correlation with cisunsaturated fatty acids while negative correlation with trans-unsaturated fatty acids and average length [62-64]. Data of RNA-Seq-based transcriptomics and metabolomics manifested that Ac can suppress fatty acid biosynthesis by down-regulating the expression of key genes such as fas1, acc1 and pox1, and strengthen fatty acid chain elongation by upregulating expression of $m c t 1$ and elo1 [2]. Similar results achieved in this study, demonstrating that the total content of fatty acids no matter saturated or unsaturated sharply reduced under Ac exposure. Interestingly, the deficiency of Atg22p likely promotes fatty acids synthesis which leads $\operatorname{Atg} 22 \Delta$ strain to accumulate more fatty acids. S. cerevisiae increased the biosynthesis of long-chain unsaturated fatty acids and reduced the biosynthesis of short-chain fatty acids to relieve membrane disruption and integrity decrease induced by Ac $[39,40,41]$. The data indicate that atg 22 deletion may reduce the destruction of membrane structure and function as well as PCD upon harsh condition [39].

\section{Amino acids balance}

Amino acids play essential roles in primary metabolites including protein synthesis, energy conversion, signaling pathways, therefore starvation for essential amino acids like lysine or histidine may induce severe cell stress, increased sensitivity to inhibitor and even PCD [16, 65, 66]. It is reported that Ac can repress the expression of numerous critical genes encoding protein about amino acid uptake, transportation and synthesis $[5,6,10,16]$. Previous researches also revealed that supplementing the corresponding amino acid or upregulating expression of genes involved in sensing, signaling and uptake of amino acids increased cell survivability under Ac, for example, the presence of proline can relieve Ac toxic effect $[14,31]$. To a certain degree, the maximal tolerance to Ac is dependent on a persistent and efficient capacity for acquiring available amino acids to maintain a basic physiological function in S. cerevisiae. Autophagy is a relatively moderate stress adaptation and self-protection tactic in extreme conditions which supplements nutrients by degrading damaged proteins as well as defective organelles in vacuoles and recycling available substances into cytoplasm to maintain cell metabolism essential for cell survival [67]. Atg22p has been proved to be a vacuolar effluxer for recycling amino acids from autophagic degradation under nitrogen starvation [15]. We found that atg22 disruption can upregulate the expression of autophagy-related genes which may enhance autophagy. What's more, atg22 deletion decreased vacuole amino acid without influencing the total content. The content of cytosolic amino acid including Thr, Glu, Pru, Gly, Met, Leu, Lys, Arg all increased in atg22 $\Delta$ except Ala which may relieve the repression of amino acids uptake induced by Ac. Based on these results, we inferred that atg 22 deficiency may strengthen yeast cells viability under Ac pressure by promoting autophagy and amino acids fluxion from vacuole to cytoplasm which supplemented available amino acids in cytoplasm and alleviated Ac toxic effect [6]. Besides, the upregulation of pep4, rgi1 and btn2 may provide additional security for $A \operatorname{tg} 22 \Delta$ cells [68]. To sum up, we supposed that Atg22p is the key regulator 
in vacuole affecting the balance of amino acids between cytosol and vacuole (Fig. 11).

\section{Stress sensing}

The heat shock protein family has been widely reported as important regulators of apoptosis [69, 70], and allows the cells to survive under a wide variety of physiological and environmental stresses [71]. Hsp70 displays an anti-apoptotic activity by inhibiting caspase activation and apoptosis-inducing factor (Aif1) release in mammalian cells [72, 73]. Hsp 90 played dual role of in acetic acid-induced apoptosis [74]. In addition, Fes1p promotes ubiquitin-dependent degradation of misfolded proteins interacted with $h s p 70$ chaperones [75]. Heat shock protein 104 (hsp104) is required for refolding and reactivating denatured and aggregated proteins cooperating with hsp 70/40 [76]. In Atg22 $\Delta$ cells, hsp 104, hsp 70 and $h s p 90$ chaperones are upregulated in response to Ac, which in accord with the previous study and indicate that stressinduced misfolded and damaged proteins are efficiently removed or reactivated by HSPs. This will contribute to maintaining protein homeostasis to protect cells against acetic acid attack (Fig. 13).

\section{Conclusions}

In conclusion, we demonstrate that $\operatorname{atg} 22$ deficiency protects cells from Ac attack through reducing ROS production and mitochondrial membrane potential. Overexpression of $\operatorname{atg} 22$ aggravates acetic acid-induced cell death, which in turn makes yeast cells to cut down the expression of Atg22p in response to Ac. Moreover, Atg22p deficiency alters the compositions of cell wall and cytomembrane to maintain their structure and function. The Atg22 $\Delta$ mutant accumulates high quantity of intracellular amino acids into the vacuole; a decrease of available amino acids delayed the cell death process during Ac treatment. In addition, Atg22 $\Delta$ cells improve the transcription of genes in heat shock protein family, cell wall integrity pathway and autophagy, which protect cells against Ac stress. On the whole, this study provides new insights for the role of Atg22p in PCD induced by Ac, and presents a novel strategy to construct industrial yeast with high acid resistance for biofuel production.

\section{Materials and methods}

\section{Strains and plasmids}

Saccharomyces cerevisiae strains BY4742 (MAT $\alpha$

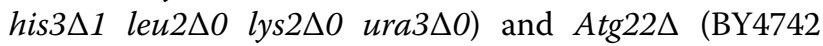
Atg22::KanMX4) used in this study were obtained from EUROSCARF. To construct the plasmid pESC-ATG22, the insert was amplified by PCR using genomic DNA of BY4742 as the template, ligated into the vector pESC-ura (Agilent Technologies) by homologous recombination using ClonExpress ${ }^{\mathrm{TM}}$ II One Step Cloning Kit (Vazyme Biotech, Nanjing, China). The plasmid pTEF-ATG22EGFP was constructed from pTEF2 by ClonExpress MultiS One Step Cloning Kit (Vazyme Biotech, Nanjing, China), with genomic DNA of BY4742 and the plasmid p416ADH-PEP4-GFP (a gift from Dr. Vítor Costa) as the templates. The wild-type BY4742 was transformed with the empty vector (pESC-ura) and pESC-ATG22 for comparison of $\operatorname{atg} 22$ overexpression in yeast. And the wildtype strain was transformed with pTEF-ATG22-EGFP for Atg22p tagging, and the empty vector pTEF2 served as control. All strains were transformed by the lithium acetate method, and validated by PCR analysis and gene sequencing. The primers and restriction enzymes for the recombinant plasmids are listed in Additional file 1: Table S5.

\section{Yeast growth and acetic acid treatment}

All yeast strains were grown in synthetic complete medium [SC; $2 \%(\mathrm{w} / \mathrm{v})$ D-glucose, $0.67 \%(\mathrm{w} / \mathrm{v})$ yeast nitrogen base without amino acids, $0.008 \%(\mathrm{w} / \mathrm{v})$ histidine, $0.02 \%(\mathrm{w} / \mathrm{v})$ leucine, $0.003 \%(\mathrm{w} / \mathrm{v})$ lysine and $0.032 \%(\mathrm{w} / \mathrm{v})$ uracil] to exponential phase in an orbital shaker, at $28{ }^{\circ} \mathrm{C}$ and $180 \mathrm{rpm}$. The strains carrying plasmids were grown in the same medium, but without uracil. For yeast cells harboring pESC-ura or pESCATG22, 2\% (w/v) galactose was used for the induction of target protein expression instead of $2 \%(\mathrm{w} / \mathrm{v}) \mathrm{D}$-glucose. For all experiments treated with acetic acid, yeast strains were grown under the above conditions until exponential phase, collected and resuspended with a final cell concentration of $1 \times 10^{7}$ cells $/ \mathrm{ml}$ in fresh SC or SG broths at pH 3.0 (set with $\mathrm{HCl}$ ) containing $150 \mathrm{mM}$ acetic acid, and incubated at $28^{\circ} \mathrm{C}$ in an orbital shaker at $160 \mathrm{rpm}$, with a ratio of flask volume/medium of 5:1. The control groups were treated without Ac under same culture conditions. Growth curves of BY4742 and $\operatorname{Atg} 22 \Delta$ were calculated by measuring $\mathrm{OD}_{600}$.

\section{Cell viability assay}

Both WT and mutant cells in exponential phase were treated with different concentrations of acetic acid (50,

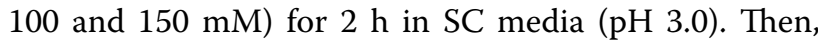
cell numbers were calculated, and 400 cells in each independent experiment were spread on YPD $[1 \%(\mathrm{w} / \mathrm{v})$ yeast extract, $2 \%(\mathrm{w} / \mathrm{v})$ peptone, $2 \%(\mathrm{w} / \mathrm{v})$ glucose and $2 \%(\mathrm{w} / \mathrm{v})$ agar] agar plates. Cell viability was measured by counting colony-forming units (CFU) after 3 days of incubation at $30{ }^{\circ} \mathrm{C}$. 


\section{Annexin V/PI costaining and DHE staining}

Phosphatidylserine externalization and loss of plasma membrane integrity were detected by flow cytometry (FC500MCL, Beckman Coulter, Brea, USA), using the Annexin V/PI apoptosis kit (Lianke, Hangzhou, China). Before that, cells were harvested and washed in sorbitol buffer (1.2 M sorbitol, $0.5 \mathrm{mM} \mathrm{MgCl} 2,35 \mathrm{mM} \mathrm{K}_{2} \mathrm{HPO}_{4}$, $\mathrm{pH}$ 6.8), digested with $20 \mathrm{U} / \mathrm{ml}$ lyticase (Sigma-Aldrich) at $30{ }^{\circ} \mathrm{C}$ for $50 \mathrm{~min}$. Subsequently, cells were washed and resuspended in $500 \mu \mathrm{l}$ of binding buffer $(1.2 \mathrm{M}$ sorbitol, $10 \mathrm{mM}$ HEPES/NaOH, $140 \mathrm{mM} \mathrm{NaCl}, 2.5 \mathrm{mM} \mathrm{CaCl}_{2}, \mathrm{pH}$ 7.4), then incubated with Annexin V and PI for 10 min at room temperature in the dark.

To quantify intracellular ROS, cells were firstly harvested and resuspended in $500 \mu \mathrm{l}$ PBS and stained with $5 \mu \mathrm{g} / \mathrm{ml}$ dihydroethidium (DHE) (Cayman Chemical, Ann Arbor, USA) for $30 \mathrm{~min}$ in the dark at room temperature [77]. Cells with red fluorescence [FL-3 channel $(488 / 620 \mathrm{~nm})]$ were detected using the Cytomics FC500MCL flow cytometer (Beckman Coulter).

\section{Atg22 $p$ tagging and $\mathrm{PI}$ staining}

For Atg22p labeling, cells carrying the plasmid pTEFATG22-EGFP were observed using a Zeiss LSM 780 confocal microscope (Carl Zeiss MicroImaging, Göttingen, Germany). The strains were grown and treated with or without acetic acid (150 mM, pH 3.0) for different times as described in the above conditions, then immobilized in the slides prior to confocal microscopy. Propidium iodide (PI) (Lianke, Hangzhou, China) staining was used to analyze the relevance between Atg22p expression and acetic acid-induced cell death. In addition, the positive cells stained by PI and cells with GFP fluorescence were quantified by flow cytometry.

\section{Morphology observation}

Scanning electron microscopy (SEM) and transmission electron microscopy (TEM) were used to observe the surface and interior structure, respectively, as previous studies noted. In short, after double fixation, dehydration SEM samples were coated with gold-palladium in Hitachi Model E-1010 ion sputter for 4-5 min and observed in Hitachi Model SU-8010 SEM. After pretreatment the steps consisted of double fixation, dehydration, infiltration, Spurr resin embedding and ultrathin section. Sections of TEM specimen were stained and observed in Hitachi Model H-7650 TEM.

\section{Extraction and measurement of cell wall polysaccharides by high-performance liquid chromatography (HPLC)}

All experimental strains were treated with different concentrations of acetic acid $(0$ and $150 \mathrm{mM})$ for $2 \mathrm{~h}$ after reaching exponential phase in SC media ( $\mathrm{pH}$ 3.0), harvested and washed thrice with distilled water by resuspension and centrifugation at $12,000 \times g$ for $5 \mathrm{~min}$ at $4{ }^{\circ} \mathrm{C}$. Cells were collected and broken by ultrasonic cell disruptor completely. After twice centrifugation and resuspension, the underlayer deposition containing cell wall was gathered and freeze-dried. About $20 \mathrm{mg}$ specimen was treated with $150 \mu \mathrm{l} 72 \%(\mathrm{~W} / \mathrm{V})$ concentrated sulfuric acid overnight and boiled $4 \mathrm{~h}$. Saturated $\mathrm{Ba}(\mathrm{OH})_{2}$ added to terminated reaction until reaching neutral $\mathrm{pH}$. Supernatant was injected into HPLC (Waters E2695, USA) for detection after centrifugation at $12,000 \times g$ for $5 \mathrm{~min}$ at $4{ }^{\circ} \mathrm{C}$ and filtration of $0.22 \mu$ membrane as previously described.

\section{Measurement of fluorescence anisotropy}

1,6-Diphenyl-1,3,5-hexatriene (TMA-DPH) was used as probe to detect the membrane fluidity of Saccharomyces cerevisiae cells in logarithmic phase as previous study described. In brief, all strains were treated with acetic acid ( $150 \mathrm{mM}, \mathrm{pH} 3.0$ ) or equal volume PBS for $120 \mathrm{~min}$ after reaching exponential phase cultured in SC media ( $\mathrm{pH} 3.0)$ and reacted with $2 \mu \mathrm{l}$ probe $(1 \mathrm{mM}) 10 \mathrm{~min}$ in dark situation. A spectrofluorimeter (Photon Technology International, Princeton, NJ, USA) with excitation at $360 \mathrm{~nm}$ and emission at $450 \mathrm{~nm}$ was applied to measure the steady-state fluorescence anisotropy. The fluorescence anisotropy value $(r)$ was calculated using the following formula:

$$
r=\left(I_{\mathrm{VV}}-G I_{\mathrm{VH}}\right) /\left(I_{\mathrm{VV}}+G I_{\mathrm{VH}}\right), \quad G=I_{\mathrm{HV}} / I_{\mathrm{HH}},
$$

where $I$ represents the correlation factor for instrument polarization and fluorescence intensity; VV indicates the measurement of both polarizers positioned vertically, the opposite of $\mathrm{HH}$; $\mathrm{VH}$ indicates the measurement of excitation in vertical emission polarizers horizontal positions which is opposite to HV. Triplicate treatment implemented during all tests and negative correlation showed between $r$ and membrane fluidity.

\section{Extraction and measurement of membrane fatty acid by gas chromatography (GC)}

Cells were freeze-dried after cultivation, treatment, and collection implemented as above. About $50 \mathrm{mg}$ samples were used for extraction and methyl esterification of total lipids before gas chromatography detection was carried out. By passage through a polyethylene glycol capillary column, components were separated and calculated as previously study described. 


\section{Membrane sterol extraction and measurement by GC- mass spectrometry (GC-MS)}

The cultivation, treatment, collection and lyophilization of Saccharomyces cerevisiae cells were implemented as above. After $40 \mu \mathrm{l}$ cholesterol $(0.5 \mathrm{mg} / \mathrm{ml})$ was added into $50 \mathrm{mg}$ freeze-dried samples as an internal standard sterol, all pretreatment processes and detection methods of gas chromatograph-mass spectrometer were operated as previous described.

\section{Membrane phospholipid extraction and measurement by LC-mass spectrometry (LC-MS)}

Freeze-dried samples were obtained as described above, $55 \mathrm{mg}$ dried specimen was weighed and used for phospholipid extraction. After six steps contained chloroform-methanol (2:1, vol/vol) treatment, vortex, ultrasound, organic phase collection, and dried under a nitrogen stream. Then, phospholipid extractive dissolved in chloroform-methanol $(1: 1, \mathrm{vol} / \mathrm{vol})$ and analyzed by electrospray ionization mass spectrometry (UPLC-Xevo TQ MS, USA) as previous described.

\section{Measurement of intracellular amino acids}

Before amino acids determination, $100 \mathrm{mg}$ fresh yeast cells were collected and washed by centrifugation after treatment with $150 \mathrm{mM}$ acetic acid ( $\mathrm{pH}$ 3.0) for $120 \mathrm{~min}$, and frozen in liquid nitrogen. The equivalent cells of BY4742 and Atg22 $\Delta$ with acetic acid treatment were used for extraction of vacuolar and total amino acid pools by the $\mathrm{Cu}^{2+}$ method as given in references $[18,78,79]$. In brief, the collected cells were washed twice with distilled water and incubated in Buffer A (2.5 mM potassium phosphate buffer, $\mathrm{pH} 6.0,0.6 \mathrm{M}$ sorbitol, $10 \mathrm{mM}$ glucose, and $0.2 \mathrm{mM} \mathrm{CuC1} 1_{2}$ ) at $30{ }^{\circ} \mathrm{C}$ for $10 \mathrm{~min}$. Then cell suspensions were filtered with $0.45-\mu \mathrm{m}$ membrane filters (Millipore) and washed 5 times with Buffer A without $0.2 \mathrm{mM} \mathrm{CuCl}$. The retained cells were resuspended in distilled water and boiled for $15 \mathrm{~min}$. The supernatant was subsequently collected as the vacuolar extract after centrifugation at $25,000 \times g$ for $3 \mathrm{~min}$. For total intracellular extracts, yeast cells were washed twice with Buffer A without $0.2 \mathrm{mM} \mathrm{CuCl}$, suspended in distilled water followed with same procedures as above. These extracts were analyzed using a Hitachi L-8900 amino acid analyzer (Hitachi, Tokyo, Japan).

\section{RNA isolation and RT-qPCR}

Total RNA was extracted from yeast cells using the E.Z.N.A. ${ }^{\circledR}$ Yeast RNA Kit (OMEGA Bio-tek, Norcross, USA), following the manufacturer's protocols. The genomic DNA contamination was eliminated and total RNA was reverse-transcribed to $\mathrm{cDNA}$ using the HiScript $^{\circledR}$ Q RT SuperMix for qPCR (+gDNA wiper) (Vazyme Biotech, Nanjing, China). For quantitative real-time (qPCR) analysis, $30 \mathrm{ng}$ of cDNA was analyzed with ChamQ SYBR qPCR Master Mix (Vazyme Biotech, Nanjing, China) according to the manufacturer's instructions, using CFX Touch ${ }^{\mathrm{TM}}$ Real-Time PCR Detection System (Bio-Rad, Hercules, USA). Relative quantification was performed by the $2^{-\Delta \Delta \mathrm{Ct}}$ method. ACT1 gene was used to quantify the mRNA levels of all genes. All primers for qPCR were designed using Primer Premier 6.0 software (PREMIER Biosoft International), and the sequences were included in Additional file 1: Table S6. Gene-specific amplification was verified by melting curve analysis and agarose gel electrophoresis.

\section{Supplementary information}

Supplementary information accompanies this paper at https://doi. org/10.1186/s13068-019-1638-x.

Additional file 1. Additional figure and tables.

\section{Abbreviations}

PCD: programmed cell death; Ac: acetic acid; HMF: hydroxymethyl furfural; ATP: adenosine triphosphate; RT-qPCR: real-time quantitative polymerase chain reaction; CFU: colony-forming units; WT: wild-type; OD 600: optical density at $600 \mathrm{~nm}$; SC media: 2\% (w/v) D-glucose, 0.67\% (w/v) yeast nitrogen base without amino acids, $0.008 \%(\mathrm{w} / \mathrm{v})$ histidine, $0.02 \%(\mathrm{w} / \mathrm{v})$ leucine, $0.003 \%(\mathrm{~W} / \mathrm{v})$ lysine and $0.032 \%(\mathrm{~W} / \mathrm{v})$ uracil; SG media: $2 \%(\mathrm{~W} / \mathrm{v})$ galactose, $0.67 \%(\mathrm{~W} / \mathrm{v})$ yeast nitrogen base without amino acids, $0.008 \%(\mathrm{~W} / \mathrm{v})$ histidine, $0.02 \%(\mathrm{w} / \mathrm{v})$ leucine, $0.003 \%(\mathrm{w} / \mathrm{v})$ lysine and $0.032 \%(\mathrm{w} / \mathrm{v})$ uracil; LB medium: $0.5 \%$ yeast extract, $1 \%$ tryptone and $1 \% \mathrm{NaCl}$; YPD medium: $1 \%$ yeast extract, $2 \%$ peptone and $2 \%$ glucose; PCR: polymerase chain reaction; DCW: dry cell weight; PI: propidium iodide; ROS: reactive oxygen species; DHE: dihydroethidium; EGFP: enhanced green fluorescent protein; MFI: mean fluorescence intensity; SEM: scanning electron microscopy; TEM: transmission electron microscopy; CWI pathway: cell wall integrity pathway; PG: phosphatidyl glycerol; PA: phosphatidic acid; PS: phosphatidylserine; PI: phosphatidylinositol; PE: phosphatidylethanolamine; PC: phosphocholine; MEHP: mono-(2-ethylhexyl)-phthalate; HPLC: high-performance liquid chromatography; TMA-DPH: 1,6-diphenyl-1,3,5-hexatriene; GC: gas chromatography; GC-MS: GC-mass spectrometry; LC-MS: LC-mass spectrometry.

\section{Acknowledgements}

We thank Bojing Liu from Institute of Feed Sciences, Zhejiang University, for helping the composition detection of cell wall and cell membrane. We thank Liming Liu from State Key Laboratory of Food Science and Technology, Jiangnan University, for helping cell membrane fluidity measure. We express gratitude to Bio-ultrastructure analysis Lab. of Analysis center of Agrobiology and environmental sciences, Zhejiang Univ for SEM and TEM observation.

\section{Authors' contributions}

$J$ : experimental design, establishment of methods, performing experiment, data analysis, writing and revising article. YD: experimental design, data analysis, writing original draft. HL: performing experiment and data arrangement. WW: amino acid detection, establishment of methods. Wei Zhang: revising and providing critical comments for this manuscript. QC: supervision, funding acquisition, experimental design, establishment of methods project administration, writing review and editing. All authors read and approved the final manuscript. 


\section{Funding}

National Natural Science Foundation of China for their financial support (No. 31871904) and the National Hi-tech Research and Development Program of China (863 Program) (No. 2007AA10Z315).

\section{Availability of data and materials}

The data sets analyzed during the current study are available from the corresponding author on reasonable request.

\section{Ethics approval and consent to participate} Not applicable.

\section{Consent for publication}

All authors read and approved the final manuscript.

\section{Competing interests}

The authors declare that they have no competing interests.

\section{Author details}

${ }^{1}$ Department of Food Science and Nutrition, Key Laboratory for Food Microbial Technology of Zhejiang Province, Zhejiang University, Hangzhou 310058, China. ${ }^{2}$ Department of Cardiovascular \& Metabolic Sciences, The Lerner Research Institute, Cleveland Clinic, Cleveland, OH, USA. ${ }^{3}$ Institute of Quality and Standard for Agriculture Products, Zhejiang Academy of Agricultural Sciences, Hangzhou 310021, China.

Received: 18 October 2019 Accepted: 12 December 2019 Published online: 27 December 2019

\section{References}

1. Gonzalez-Ramos D, de Vries ARG, Grijseels SS, van Berkum MC, Swinnen S, van den Broek M, Nevoigt E, Daran J-MG, Pronk JT, van Maris AJA. A new laboratory evolution approach to select for constitutive acetic acid tolerance in Saccharomyces cerevisiae and identification of causal mutations. Biotechnol Biofuels. 2016;9:173.

2. Dong Y, Hu J, Fan L, Chen Q. RNA-Seq-based transcriptomic and metabolomic analysis reveal stress responses and programmed cell death induced by acetic acid in Saccharomyces cerevisiae. Sci Rep. 2017;7:42659.

3. Cunha JT, Romani A, Costa CE, Sa-Correia I, Domingues L. Molecular and physiological basis of Saccharomyces cerevisiae tolerance to adverse lignocellulose-based process conditions. Appl Microbiol Biotechnol. 2019;103:159-75.

4. Palma M, Guerreiro JF, Sa-Correia I. Adaptive response and tolerance to acetic acid in Saccharomyces cerevisiae and Zygosaccharomyces bailii: a physiological genomics perspective. Front Microbiol. 2018;9:274.

5. Bauer BE, Rossington D, Mollapour M, Mamnun Y, Kuchler K, Piper PW. Weak organic acid stress inhibits aromatic amino acid uptake by yeast, causing a strong influence of amino acid auxotrophies on the phenotypes of membrane transporter mutants. Eur J Biochem. 2003;270:3189-95.

6. Almeida B, Ohlmeier S, Almeida AJ, Madeo F, Leao C, Rodrigues F, Ludovico P. Yeast protein expression profile during acetic acid-induced apoptosis indicates causal involvement of the TOR pathway. Proteomics. 2009;9:720-32.

7. Nielsen J, Larsson C, van Maris A, Pronk J. Metabolic engineering of yeast for production of fuels and chemicals. Curr Opin Biotechnol. 2013;24:398-404.

8. Zhang M-M, Xiong L, Tang Y-J, Mehmood MA, Zhao ZK, Bai F-W, Zhao X-Q. Enhanced acetic acid stress tolerance and ethanol production in Saccharomyces cerevisiae by modulating expression of the de novo purine biosynthesis genes. Biotechnol Biofuels. 2019;12:116.

9. Wei N, Quarterman J, Kim SR, Cate JHD, Jin YS. Enhanced biofuel production through coupled acetic acid and xylose consumption by engineered yeast. Nat Commun. 2013;4:2580.

10. Ding J, Bierma J, Smith MR, Poliner E, Wolfe C, Hadduck AN, Zara S, Jirikovic $\mathrm{M}$, van Zee $\mathrm{K}$, Penner $\mathrm{MH}$, et al. Acetic acid inhibits nutrient uptake in Saccharomyces cerevisiae: auxotrophy confounds the use of yeast deletion libraries for strain improvement. Appl Microbiol Biotechnol. 2013;97:7405-16.
11. Hueso G, Aparicio-Sanchis R, Montesinos C, Lorenz S, Murguia JR, Serrano R. A novel role for protein kinase $\mathrm{Gcn} 2$ in yeast tolerance to intracellular acid stress. Biochem J. 2012;441:255-64.

12. Almeida B, Buettner $S$, Ohlmeier S, Silva A, Mesquita A, Sampaio-Marques B, Osorio NS, Kollau A, Mayer B, Leao C, et al. NO-mediated apoptosis in yeast. J Cell Sci. 2007;120:3279-88.

13. Schuller C, Mamnun YM, Mollapour M, Krapf G, Schuster M, Bauer BE, Piper PW, Kuchler K. Global phenotypic analysis and transcriptional profiling defines the weak acid stress response regulon in Saccharomyces cerevisiae. Mol Biol Cell. 2004;15:706-20.

14. Greetham D, Takagi $H$, Phister TP. Presence of proline has a protective effect on weak acid stressed Saccharomyces cerevisiae. Antonie Van Leeuwenhoek Int J Gen Mol Microbiol. 2014;105:641-52.

15. Yang ZF, Klionsky DJ. Permeases recycle amino acids resulting from autophagy. Autophagy. 2007;3:149-50.

16. Li BZ, Yuan YJ. Transcriptome shifts in response to furfural and acetic acid in Saccharomyces cerevisiae. Appl Microbiol Biotechnol. 2010;86:1915-24.

17. Ludovico P, Sousa MJ, Silva MT, Leao C, Corte-Real M. Saccharomyces cerevisiae commits to a programmed cell death process in response to acetic acid. Microbiology. 2001;147:2409-15.

18. Yang Z, Huang J, Geng J, Nair U, Klionsky DJ. Atg22 recycles amino acids to link the degradative and recycling functions of autophagy. Mol Biol Cell. 2006;17:5094-104.

19. Lee Y, Nasution O, Choi E, Choi I-G, Kim W, Choi W. Transcriptome analysis of acetic-acid-treated yeast cells identifies a large set of genes whose overexpression or deletion enhances acetic acid tolerance. Appl Microbiol Biotechnol. 2015;99:6391-403.

20. Zhou Q, Liu ZL, Ning K, Wang AH, Zeng XW, Xu J. Genomic and transcriptome analyses reveal that MAPK-and phosphatidylinositol-signaling pathways mediate tolerance to 5-hydroxymethyl-2-furaldehyde for industrial yeast Saccharomyces cerevisiae. Sci Rep. 2014;4:6556.

21. Zhao S, Liu Q, Wang J-X, Liao X-Z, Guo H, Li C-X, Zhang F-F, Liao L-S, Luo $X-M$, Feng J-X. Differential transcriptomic profiling of filamentous fungus during solid-state and submerged fermentation and identification of an essential regulatory gene PoxMBF1 that directly regulated cellulase and xylanase gene expression. Biotechnol Biofuels. 2019;12:103.

22. Martins VM, Fernandes TR, Lopes D, Afonso CB, Domingues MRM, CorteReal M, Sousa MJ. Contacts in death: the role of the ER-mitochondria axis in acetic acid-induced apoptosis in yeast. J Mol Biol. 2019;431:273-88.

23. Pan S, Jia B, Liu H, Wang Z, Chai M-Z, Ding M-Z, Zhou X, Li X, Li C, Li B-Z, Yuan $Y$-J. Endogenous lycopene improves ethanol production under acetic acid stress in Saccharomyces cerevisiae. Biotechnol Biofuels. 2018;11:107.

24. Niles BJ, Joslin AC, Fresques T, Powers T. TOR complex 2-Ypk1 signaling maintains sphingolipid homeostasis by sensing and regulating ROS accumulation. Cell Rep. 2014;6:541-52.

25. Woo JM, Yang KM, Kim SU, Blank LM, Park JB. High temperature stimulates acetic acid accumulation and enhances the growth inhibition and ethanol production by Saccharomyces cerevisiae under fermenting conditions. Appl Microbiol Biotechnol. 2014;98:6085-94.

26. Guerreiro JF, Sampaio-Marques B, Soares R, Coelho AV, Leao C, Ludovico P, Sa-Correia I. Mitochondrial proteomics of the acetic acid-induced programmed cell death response in a highly tolerant Zygosaccharomyces bailii-derived hybrid strain. Microb Cell. 2016;3:65-78.

27. Rego A, Duarte AM, Azevedo F, Sousa MJ, Côrte-Real M, Chaves SR. Cell wall dynamics modulate acetic acid-induced apoptotic cell death of Saccharomyces cerevisiae. Microb Cell. 2014;1:303-14.

28. Simoes T, Mira NP, Fernandes AR, Sa-Correia I. The SPI1 gene, encoding a glycosylphosphatidylinositol-anchored cell wall protein, plays a prominent role in the development of yeast resistance to lipophilic weak-acid food preservatives. Appl Environ Microbiol. 2006;72:7168-75.

29. Mollapour M, Shepherd A, Piper PW. Presence of the Fps $1 \mathrm{p}$ aquaglyceroporin channel is essential for Hog1p activation, but suppresses Slt2(Mpk1)p activation, with acetic acid stress of yeast. Microbiology. 2009;155:3304-11.

30. Da WY, Shao J, Li QQ, Shi GX, Wang TM, Wu DQ, Wang CZ. Physical interaction of sodium houttuyfonate with beta-1,3-glucan evokes Candida albicans cell wall remodeling. Front Microbiol. 2019;10:9.

31. Mira NP, Palma M, Guerreiro JF, Sa-Correia I. Genome-wide identification of Saccharomyces cerevisiae genes required for tolerance to acetic acid. Microb Cell Fact. 2010;9:79. 
32. Walker LA, Gow NA, Munro CA. Elevated chitin content reduces the susceptibility of Candida species to caspofungin. Antimicrob Agents Chemother. 2013;57:146-54.

33. Pan HP, Wang N, Tachikawa H, Nakanishi H. Beta-1,6-glucan synthesisassociated genes are required for proper spore wall formation in Saccharomyces cerevisiae. Yeast. 2017;34:431-46.

34. Molon M, Woznicka O, Zebrowski J. Cell wall biosynthesis impairment affects the budding lifespan of the Saccharomyces cerevisiae yeast. Biogerontology. 2018;19:67-79.

35. Robertson JL. The lipid bilayer membrane and its protein constituents. J Gen Physiol. 2018;150:1472-83.

36. Stratford M, Nebe-von-Caron G, Steels H, Novodvorska M, Ueckert J, Archer DB. Weak-acid preservatives: $\mathrm{pH}$ and proton movements in the yeast Saccharomyces cerevisiae. Int J Food Microbiol. 2013;161:164-71.

37. Ullah A, Orij R, Brul S, Smits GJ. Quantitative analysis of the modes of growth inhibition by weak organic acids in Saccharomyces cerevisiae. Appl Environ Microbiol. 2012;78:8377-87.

38. Godinho CP, Prata CS, Pinto SN, Cardoso C, Bandarra NM, Fernandes $\mathrm{F}$, Sa-Correia I. Pdr18 is involved in yeast response to acetic acid stress counteracting the decrease of plasma membrane ergosterol content and order. Sci Rep. 2018;8:7860.

39. Guo Z-P, Khoomrung S, Nielsen J, Olsson L. Changes in lipid metabolism convey acid tolerance in Saccharomyces cerevisiae. Biotechnol Biofuels. 2018;11:297.

40. Lindberg L, Santos AX, Riezman H, Olsson L, Bettiga M. Lipidomic profiling of Saccharomyces cerevisiae and Zygosaccharomyces bailii reveals critical changes in lipid composition in response to acetic acid stress. PLOS ONE. 2013;8:e73936.

41. Zhang M, Zhang K, Mehmood MA, Zhao ZK, Bai F, Zhao X. Deletion of acetate transporter gene ADY2 improved tolerance of Saccharomyces cerevisiae against multiple stresses and enhanced ethanol production in the presence of acetic acid. Bioresour Technol. 2017;245:1461-8.

42. Guerreiro JF, Muir A, Ramachandran S, Thorner J, Sa-Correia I. Sphingolipid biosynthesis upregulation by TOR complex 2-Ypk1 signaling during yeast adaptive response to acetic acid stress. Biochem J. 2016:473:4311-25.

43. Lindahl L, Genheden S, Eriksson LA, Olsson L, Bettiga M. Sphingolipids contribute to acetic acid resistance in Zygosaccharomyces bailii. Biotechnol Bioeng. 2016;113:744-53.

44. Qi Y, Liu H, Yu J, Chen X, Liu L. Med15B regulates acid stress response and tolerance in Candida glabrata by altering membrane lipid composition. Appl Environ Microbiol. 2017;83:e01128-17.

45. Yan DN, Lin XB, Qi YL, Liu H, Chen XL, Liu LM, Chen J. Crz1p regulates pH homeostasis in Candida glabrata by altering membrane lipid composition. Appl Environ Microbiol. 2016;82:6920-9.

46. Lin XB, Qi YL, Yan DN, Liu H, Chen XL, Liu LM. CgMED3 changes membrane sterol composition to help Candida glabrata tolerate low-pH stress. Appl Environ Microbiol. 2017;83:15.

47. Sezgin E, Levental I, Mayor S, Eggeling C. The mystery of membrane organization: composition, regulation and roles of lipid rafts. Nat Rev Mol Cell Biol. 2017;18:361-74.

48. Dupont S, Lemetais G, Ferreira T, Cayot P, Gervais P, Beney L. Ergosterol biosynthesis: a fungal pathway for life on land? Evolution. 2012;66:2961-8.

49. Parsons JB, Rock CO. Bacterial lipids: metabolism and membrane homeostasis. Prog Lipid Res. 2013;52:249-76.

50. Caspeta L, Chen Y, Ghiaci P, Feizi A, Buskov S, Hallstrom BM, Petranovic D, Nielsen J. Biofuels. Altered sterol composition renders yeast thermotolerant. Science. 2014;346:75-8.

51. Folmer V, Pedroso N, Matias AC, Lopes SC, Antunes F, Cyrne L, Marinho $\mathrm{HS} . \mathrm{H}_{2} \mathrm{O}_{2}$ induces rapid biophysical and permeability changes in the plasma membrane of Saccharomyces cerevisiae. Biochem Biophys Acta. 2008:1778:1141-7.

52. Neumann A, Baginski M, Winczewski S, Czub J. The effect of sterols on amphotericin B self-aggregation in a lipid bilayer as revealed by free energy simulations. Biophys J. 2013;104:1485-94.

53. Abe F, Hiraki T. Mechanistic role of ergosterol in membrane rigidity and cycloheximide resistance in Saccharomyces cerevisiae. Biochimica Et Biophysica Acta. 2009;1788:0-752.

54. Andrade JC, Braga MFBM, Guedes GMM, Tintino SR, Freitas MA, Quintans $\mathrm{LJ} \mathrm{Jr}$, Menezes IRA, Coutinho HDM. Menadione (vitamin K) enhances the antibiotic activity of drugs by cell membrane permeabilization mechanism. Saudi J Biol Sci. 2017;24:59-64.

55. Qi Y, Liu H, Chen X, Liu L. Engineering microbial membranes to increase stress tolerance of industrial strains. Metab Eng. 2019;53:24-34

56. Bhattacharya S, Esquivel BD, White TC. Overexpression or deletion of ergosterol biosynthesis genes alters doubling time, response to stress agents, and drug susceptibility in Saccharomyces cerevisiae. mBio. 2018;9:e01291-18.

57. Jiang L, Wang L, Fang T, Papadopoulos V. Disruption of ergosterol and tryptophan biosynthesis, as well as cell wall integrity pathway and the intracellular $\mathrm{pH}$ homeostasis, lead to mono-(2-ethylhexyl)-phthalate toxicity in budding yeast. Chemosphere. 2018;206:643-54.

58. Dong SJ, Yi CF, Li H. Changes of Saccharomyces cerevisiae cell membrane components and promotion to ethanol tolerance during the bioethanol fermentation. Int J Biochem Cell Biol. 2015;69:196-203.

59. Wang Y, Zhang S, Liu H, Zhang L, Yi C, Li H. Changes and roles of membrane compositions in the adaptation of Saccharomyces cerevisiae to ethanol. J Basic Microbiol. 2015;55:1417-26.

60. Henderson CM, Block DE. Examining the role of membrane lipid composition in determining the ethanol tolerance of Saccharomyces cerevisiae. Appl Environ Microbiol. 2014;80:2966-72.

61. Kamthan A, Kamthan M, Datta A. Expression of C-5 sterol desaturase from an edible mushroom in fission yeast enhances its ethanol and thermotolerance. PLoS ONE. 2017;12:e0173381.

62. Tan Z, Yoon JM, Nielsen DR, Shanks JV, Jarboe LR. Membrane engineering via trans unsaturated fatty acids production improves Escherichia coli robustness and production of biorenewables. Metab Eng. 2016:35:105-13.

63. Gong Z, Nielsen J, Zhou YJ. Engineering robustness of microbial cell factories. Biotechnol J. 2017:12:1700268.

64. Besada-Lombana PB, Fernandez-Moya R, Fenster J, Da SN. Engineering Saccharomyces cerevisiae fatty acid composition for increased tolerance to octanoic acid. Biotechnol Bioeng. 2017;114:1531-8.

65. Wang S, Tsun Z-Y, Wolfson RL, Shen K, Wyant GA, Plovanich ME, Yuan ED, Jones TD, Chantranupong L, Comb W, et al. Lysosomal amino acid transporter SLC38A9 signals arginine sufficiency to mTORC1. Science. 2015:347:188-94

66. Jewell JL, Kim YC, Russell RC, Yu F-X, Park HW, Plouffe SW, Tagliabracci VS, Guan K-L. Differential regulation of $\mathrm{mTORC} 1$ by leucine and glutamine. Science. 2015;347:194-8.

67. Maiuri MC, Zalckvar E, Kimchi A, Kroemer G. Self-eating and self-killing: crosstalk between autophagy and apoptosis. Nat Rev Mol Cell Biol. 2007:8:741-52

68. Carmona-Gutiérrez D, Bauer MA, Ring J, Knauer H, Eisenberg T, Büttner S, Ruckenstuhl C, Reisenbichler A, Magnes C, Rechberger GN, et al. The propeptide of yeast cathepsin D inhibits programmed necrosis. Cell Death Dis. 2011;2:e161.

69. Takayama S, Reed JC, Homma S. Heat-shock proteins as regulators of apoptosis. Oncogene. 2003;22:9041-7.

70. Lanneau D, Brunet M, Frisan E, Solary E, Fontenay M, Garrido C. Heat shock proteins: essential proteins for apoptosis regulation. J Cell Mol Med. 2008;12:743-61.

71. Parcellier A, Gurbuxani S, Schmitt E, Solary E, Garrido C. Heat shock proteins, cellular chaperones that modulate mitochondrial cell death pathways. Biochem Biophys Res Commun. 2003;304:505-12.

72. Gurbuxani S, Schmitt E, Cande C, Parcellier A, Hammann A, Daugas E, Kouranti I, Spahr C, Pance A, Kroemer G, Garrido C. Heat shock protein 70 binding inhibits the nuclear import of apoptosis-inducing factor. Oncogene. 2003;22:6669-78.

73. Li CY, Lee JS, Ko YG, Kim JI, Seo JS. Heat shock protein 70 inhibits apoptosis downstream of cytochrome c release and upstream of caspase-3 activation. J Biol Chem. 2000;275:25665-71.

74. Silva A, Sampaio-Marques B, Fernandes A, Carreto L, Rodrigues F, Holcik $M$, Santos MAS, Ludovico P. Involvement of yeast HSP90 isoforms in response to stress and cell death induced by acetic acid. PLOS ONE. 2013;8:e71294.

75. Gowda NKC, Kandasamy G, Froehlich MS, Dohmen RJ, Andreasson C. Hsp70 nucleotide exchange factor Fes 1 is essential for ubiquitin-dependent degradation of misfolded cytosolic proteins. Proc Natl Acad Sci USA. 2013:110:5975-80 
76. Okuda M, Niwa T, Taguchi H. Single-molecule analyses of the dynamics of heat shock protein 104 (Hsp 104) and protein aggregates. J Biol Chem. 2015;290:7833-40.

77. Pereira H, Azevedo F, Rego A, Sousa MJ, Chaves SR, Côrte-Real M. The protective role of yeast cathepsin $D$ in acetic acid-induced apoptosis depends on ANT (Aac2p) but not on the voltage-dependent channel (Por1p). FEBS Lett. 2013;587:200-5.

78. Ohsumi Y, Kitamoto K, Anraku Y. Changes induced in the permeability barrier of the yeast plasma membrane by cupric ion. J Bacteriol. 1988;170:2676-82.
79. Sugimoto N, Iwaki T, Chardwiriyapreecha S, Shimazu M, Kawano M, Sekito T, Takegawa K, Kakinuma Y. Atg22p, a vacuolar membrane protein involved in the amino acid compartmentalization of Schizosaccharomyces pombe. Biosci Biotechnol Biochem. 2011;75:385-7.

\section{Publisher's Note}

Springer Nature remains neutral with regard to jurisdictional claims in published maps and institutional affiliations.
Ready to submit your research? Choose BMC and benefit from:

- fast, convenient online submission

- thorough peer review by experienced researchers in your field

- rapid publication on acceptance

- support for research data, including large and complex data types

- gold Open Access which fosters wider collaboration and increased citations

- maximum visibility for your research: over $100 \mathrm{M}$ website views per year

At BMC, research is always in progress.

Learn more biomedcentral.com/submissions 